\title{
Supply Chain System Engineering: Framework Transforming Value Chain in Business Domain into Manageable Virtual Enterprise and Participatory Production
}

\author{
Timothy P. Tsai \\ Southern Methodist University/ Texas Instruments/ \\ Flow Fusion Research Lab Dallas, Texas \\ United State
}

\section{Introduction}

After 15 years of evolution of the Internet, the e-commerce in public space is crowded with players from C2C (eBay.com), B2B (Alibaba.com), to B2C (Amazon.com) etc. The infrastructure supports a horizontal supply chain connection such as the Supply Chain Operation Reference (SCOR) model from the supply chain council, RosettaNet protocol, and cloud computing providers compiling those standards like Saleforce.com are quite mature. However, when it comes to the vertical integration in B2B for collaborative operation such as ERP, MES etc., it drops to a single digit in multiple-enterprises connectivity (Viswanathan, 2008). That Aberdeen survey indicates that the Internet revolution has very little effect on the vertical integration surprisingly in Supply Chain Management (SCM), even the Best-In-Class enterprises (Tsai el at, 2009). On the other side of society, at May 10, 2011, Google is confirmed losing its crown to facebook, the largest, single community connecting more than 640 million netizens who has been growing rapidly since 2004, with $7.49 \%$ vs. $10.4 \%$ in total internet traffic according to Hitwise. What links those two isolated phenomenon together is that they are both about hitting the wall of private space or working around on the wall among them. The requirements of privacy and security of the private space naturally block the accessibility from the public search engine giants like Google and each of connectivity among those private spaces has a unique resolution. This chapter believes that the people-centric facebook, and the newly promoting Participatory Production (PP) in this chapter are the two ends of the full spectrum of those private space solution spaces, where the multiple-enterprises solution is about in the middle. In fact, that is not a finding but rather a necessary condition to the hybrid-connected society of the postInternet era that connecting public space and private space all together.

\subsection{Extreme virtual enterprise application of private space spectrum}

The Participatory Production represents the most complicated value network in the business domain. The extreme complexity is coming from the purpose of PP model to archive and the goal of covering full spectrium of private space. It comes out the solution to $\mathrm{PP}$ is a cross-over point of 4 dimensons: 
1. The designed-in backward compatibility to the SCOR model in supply chain dimension

2. Full coverage of the DoD 5000 Acquisition Process in system engineering dimension

3. Being connectable to the social network in the social science dimension to obtain human capital on demand, and,

4. Covering technological segment in process industry

That definition sets the boundary of the PP, and, the requirements. In order to solve the management challenges of such a complicated value network, the traditional SCM is exhausted and has to be modified by adding System Engineering, Technology Management disciplines and so on into a new, redefined discipline: Supply Chain System Engineering (SCSE). Since the objective of SCSE is to serve the entire spectrum of private space, the Information Technology (IT) model it adapts has to be covering both the Enterprise Private Space (EPS) and Personal Private Space (PPS). The former connects between enterprises and the later connects between human capitals in various formats from freelancer, collaborative SME, to form a virtual organization. The PPS is a whole new concept to the people-centric domain, and that model provides a new path of connecting the social network to EPS. That path is one of the major missing puzzles of forming a nested society today. In principle, there is a human-centric PPS for any individual who can reside and accumulate his knowledge, expertise and those personal assets are transferable into career development. Ideally, it is also scalable to be a freelancer, collaborative SME, or even large enterprise. Those new capabilities in PPS enable new human capital policy, knowledge management collaboration, and new enterprise level SCM solution in PP application. In this chapter, the PPS provides a new path for the individual climbing up the social hierarchy and PP architecture allows large enterprise connecting downward to reach an individual in participating manner. That closed-loop pair provides a new dynamic circulation of ecosystem of future nested society to boot the e-society to the next energy level.

The term "Virtual Enterprise (VE)" is a neutral description on asset holding approach with unique signature of orthogonal financial boundary and operation boundary. With the SCSE and feasibility of PP application, 3 more elements are added. First, human capital is also participatory in the entire value chain, independently. That starts to make the line between enterprise and individual fading away. Second, enterprises are participating in a same business objective in a mutual beneficial manner, with a bottom-up feature similar to the social network. Third, the business objective is covering the entire product life cycle in a varied mature level to support product delivery. The last two features are enabling size independent, aggressive enterprises in the PP model. Any enterprise even a freelancer with core value can be master of a value chain with super high leverage level, and, though the long acquisition cycle. The SCSE is lowering the entrance barrier to be PP-capable in two folds: the framework developed in this chapter and the SCSE enable ecosystem empowering the freelancer or SME. For the ultra-competitive business environment in the next decade, being a Triple-A enterprise (Lee, 2004) with adaquate Agility is mandatory. In this chatper, being PP-capable is equvaelnt to be eligible as a Triple A enterprise.

\subsection{What this chapter covers}

The PP model is connecting virtual enterprise type networked entities to the social network to free up the human capital asset. The infrastructure underneath the PP pulling both individuals and enterprises into one hybrid-connected platform is a revolutionary step of human history to sustain full economic activities inside a connected complex. According to 
the potential impact scope and complexity, this chapter is taking the onion peeling strategy to strip layer by layer from society, then SCM evolution, then how to apply PP in the enterprise. The peeling process exploring what is behind and explains why the SCSE is set to be the physics of running the nested society. The multiple-layers coverage hierarcy in fig 1 is reflecting the complexity of handling such a networked architecture connecting the 4 dimesions. The right color blocks cover the full introduction of the PP topic where the SCM is the root of SCSE in the coverage hierarchy. The gray color is supporting information of SCSE either its upper level in a nested society, or what is predicted in the future development. The Level one under the SCM root is a requirement engineering process about what is required to build a value chain in SCSE. The level two is an allocation process to transform the requirements into a configuration baseline under the SCSE architecture model. The last level on the right is the realization process to transform the designed value chain topology into the functional organization of each participatory entity among the supply chain.

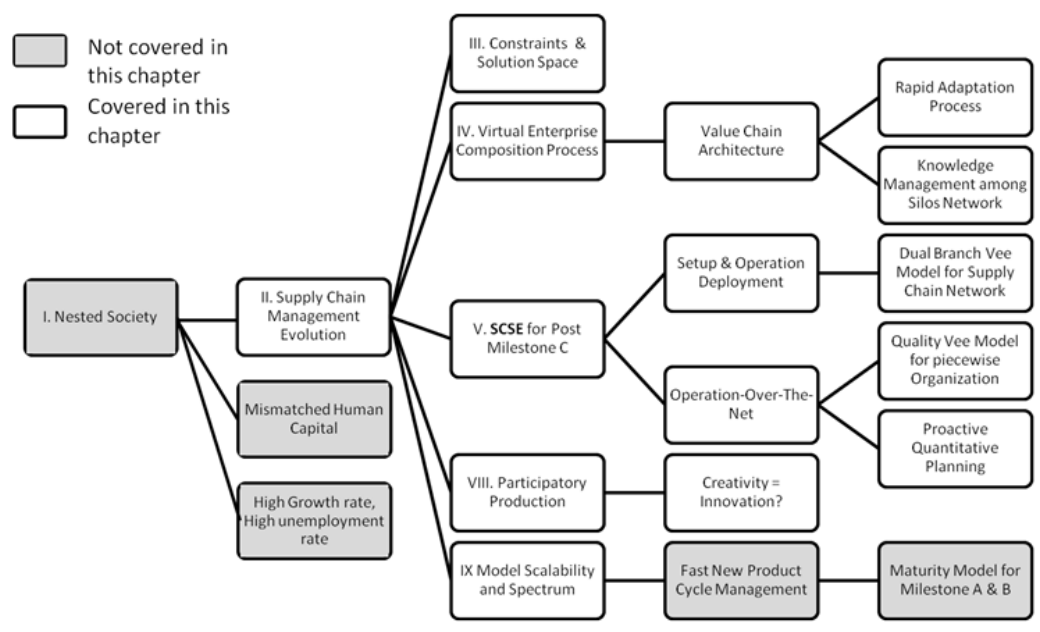

Fig. 0. This Chapter Coverage Hierarchy

Merging the System Engineering into the SCSE has another reason: applies the best practice approach in the management science aspect to solve a complex system that a single discipline cannot resolve. In the value chain domain, the current maturity level is very like the situation of the early $80 \mathrm{~s}^{\prime}$ when the acquisition cycle was poorly executed. For PP itself, is to manage science challenges for managing mega, distributed organization problems. The best-practise approach similar to the DoD 4245.7-M standard (Willoughby, 1985) that managing acqusistion cycle for a large project is adapted in this chapter. Reader shall learn how to build a Triple-A enterprise via the adaptation-Alignment process to earn his agility in a participatory manner.

\section{Evolution of nested society}

The nested society evolution today is like the Solar System five billion years ago when our Sun formed with the Bok globules in the galaxy. The connectivity is the gravity force and 
Social Network (SN) is the center of gravity of the digitizing society, or e-society. An Emmentaler-like nested society structure is forming with lots of holes which are either personal private space or enterprise private space as illustrated in fig 0 . That hypothesis of putting SN in the center of universe is pulling People back to the center of human history, not Information Technology (IT), where $\mathrm{SN}$ is the only native human-centric application not like the others (Dertouzos, 2001)

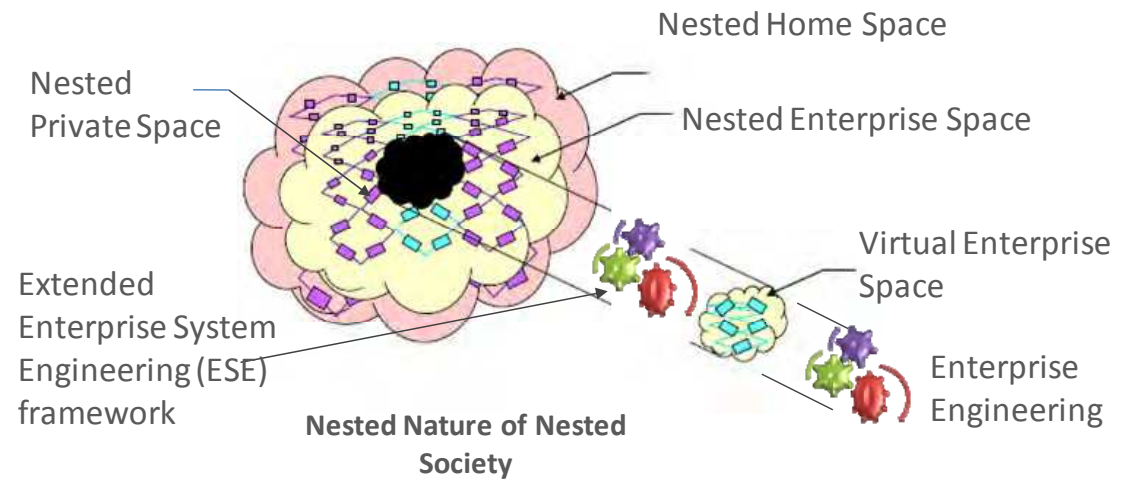

Source: Modified from George Rebovich, Jr. "Enterprise Systems Engineering Theory and Practice , Volume 2:

Systems Thinking for the Enterprise: New and Emerging Perspectives ", MITRE, Nov 2005

Fig. 1. Emmentaler-like structure for Nested Society

The original concept is from about the business environment, which is a dynamically nested structure. The enterprise is part of such a nested structure and it may contain subenterprises, each with its own people, processes, technologies, funding and other resources (Rebovich 2006). That concept was further developed to be connectable to any Supply Chain Network by adding the Extended Enterprise System Engineering layer and the Dual Branch Vee Model in architecture (Tsai et al, 2008). The definition in this chapter to have the PP as the cross-over point of the 4 dimensions completes the implementation gap. The full coverage of the private space and connectable to the $\mathrm{SN}$ to the nested society is like a lockand-key matching. This chapter is taking that nested society as the end point of the IT resolution which covers the full society in a hybrid-connected complex and it can hold all the economic activities the human needs. While pulling in the activities into the complex, it is a digitization process or transformation process which is not necessary a copy-exact but realized by new IT tools. Letter to email, book to e-Book, and department store to Amazon.com, are good examples of replacement. Some are improvement with flow innovation such as Groupon.com. Nothing change in supply and demand but much more efficient than the current practise by employing the internet-enable participatory purchasing power.

\subsection{Universe has physics and nested society has it}

It is engineering skill to set end point to trigger the continuous, iterating improvement process. Once the end point is set to be the nested society, looking back is possible. 
Interestingly, the entire IT evolution process is really like the dust particles in the cloud making up the early solar system. Once the center of gravity was established, it is staring out as an irregular cloud, and many of the dust particles in the cloud have begun to move into more regular orbits, circling the newborn star as a proto-planetary disc. That stage could be analogous to the Google era in public space. Within the cloud, large chunks of rock condensed into the planets, which processed to sweep their orbits clean of material, integrating it into themselves. That portion is not much different from the industrial revolution process such as a new startup, acquisition, merge and consolidation in enterprise, or, forming a cluster community in the social network. Besides the evolution process, there is a mechanism to be borrowed with: the classical physics. It is the science of how the Solar system running and there shall be physics to run the nested society as well. If the PP application and models behind are supporting the full spectrum of the private space, the high density fusion discipline SCSE that brings the 4 dimensions into a single cross-over point to fuel the PP application is nominating SCSE as the best candidate to perform the "physics" position that running the nested society.

The purpose of establishing the nested society model and the physics behind that is to avoid reinventing the wheel. Besides that, knowing the physics is capable to theorize the possible outcome. Taking the Groupon.com as an example, there is no new element in economy sense but a new SN based domain pulling in economic activities from current practice. It is similar with what Dell did to channel business. The physics give precise resolution of the IT evolution process as to calculate what shall be new elements, and exactly where they. With the physics, it will be much easier to know what is needed and how to build the organization to support that "new" business model as well. With that understanding, when Groupon.com localizes in the China market, he must consider the nature of SN in China is different. There are more C-2-B-2$\mathrm{B}-\mathrm{C}$ clusters, less real name netizen, less credit system on the back, and tough government control. With all that acknowledgement, the mask of IT is taken out and allow observer seeing through the intrinsic value of digitization to human binges.

\subsection{Hyper-connected feature changing paradigm}

The IT connectivity changes human history dramatically in two folds: obtaining resources and knowledge management. Before the Internet era, investment was mostly the only way to obtain resources to produce products or services to the end customer. After the network era, however, assets could be "connected" instead of invested and it changed the business landscape dramatically in all dimensions. The hybrid-connected capability in IT or telecom network is fading out the boundary of finance, operation in enterprise, now individual to enterprise. The shifting paradigm is challenging all aspects from the fields to academics all around. Tasks done by grouping talents into a single room before, is now replaced by a cluster of networked resources independent of geography and organization. The first immediate impact is a HIGH economic growing rate and a HIGH unemployment rate together. Going virtual is clearly a significant financial return advantage in the short term to enterprise when taking out resources investment as cost but keep the same revenue in virtual enterprise approach (Tsai et al, 2011). The connectivity enables alternative routes of realizing the same revenue by collaborating with partners and connecting to contractors. Those approaches are allowing enterprise to take out the top two costs from reducing investment in assets and employees in the past. The second is happening slowly but has even more fundamental impact underground: the need for human capital in the job market and the education system which is producing those human capitals. During the transition 
period of digitization, newly graduated students from school with a single discipline are most likely suffering job hunting difficulty results to a higher unemployment rate. On the other hand, the human capital market is sort of right candidates with cross-field, integrated talent. The former keep the unemployment rate high at nearly $8-10 \%$ level and the latter creates a new term "mal-employed" with about 2 million graduated students in 2011. Those are not new in human history during the transition of revolution but this time it is not coming with the classical recession together. The rapidly growing global economy and excellent earning in large enterprises due to newly added connectivity characteristics is a unique signature in the IT revolution.

With the physics in SCSE, those disruptions of society or economy could be easier to calculate and estimate about when the trend could be stopped and the rebalance could be reached. For the new features of virtual enterprise under PP application, a measurement of how well an enterprise is adapting also defined:

Trend, rebalance: theoretically, any balance is breaking and another balance will be reached sooner. The top management trained by manage-by-the number MBA discipline is taking instant advantage of the new outsourcing opportunity driving by excellent ROI of virtual enterprise. However, those optimistic short-term actions will easily be stopped when the cost of quality, lack of capacity for supply continuity, the potential threat of leaking out IP to competitors, broken development cycle or any other cost induced from outsourcing are pushing back when those loses are started appearing on the financial report.

Measurement: There is a "Degree of Freedom (DoF)" of virtual enterprise to measure about how flexible an enterprise to leverage external resources for obtaining the same revenue. For example, a business with 1:3 financial ratios is used to describe a business can only invest $1 / 3$ of the resources it needs and connect to $2 / 3$ of external resources. This definition will be used throughout this chapter. The DoF concept is a straight forward, quantitative measurement of the capitalist competitive 'freedom" concept (Nolan el at, 2007). Traditionally, the complexity of 'cascade effects" make the invisible part of the 'iceberg' to make an enterprise successful is the competitive advantage of unique workflow (Porter, 1998). The hidden cost pushing back from outsourcing is indicating that the "cascade effect" under the 'iceberg' is not transferable or sustainable easily to the outside when connecting to external resources. That is also a true statement that the size of the enterprise matters when size is representing how well the company is 'cascaded' together in a classical SCM discipline.

\subsection{Nested society transformation}

In the post-Internet era, virtual enterprise is ideally defined to be with high DoF and size independent in connectivity. That means enterprise has absolute freedom to determine who to collaborate with anytime, anywhere in value chain and only limited to the economic factor, IP protection, and strategic constraints but not quality cost, supply continuity, responsiveness of the supply chain, and the size of suppliers or partners to connect to. If enterprise space and personal space are the "holes" inside the Emmentaler-like structure of the nested society, Fig 2 below is the transformation matrix to serve that objective. The chart illustrates that the networked society having 2 more dimensions in private connectivity within a nested society which is the Product Acquisition path and Career Development path in addition to the public connectivity space in the social network and e-commerce domain. SCSE is in the center of the transformation process and it implies it is a multiple layers architecture connecting entities (Enterprise), human capital (people), resources (assets, 
material), and, the knowledge associated with those activities among the two paths in the transformation process. More detail will be elaborated in later sections. The others 2 dimensions about backward compatible to SCOR, and including Process Technology are embedded inside the chart. The former is designed-in in the virtual enterprise path, and, the later is embedded inside the product acquisition path.

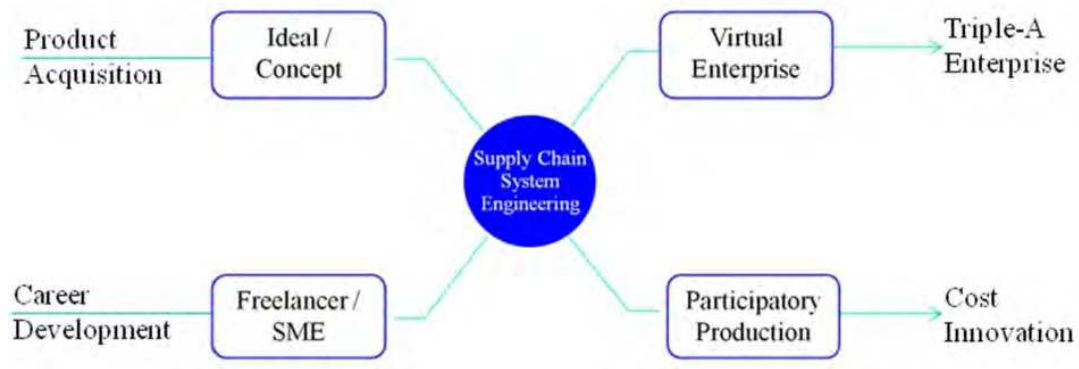

Fig. 2. Transformation Matrix

The transformation matrix is a self-explanatory chart about why it can enable connectivity among private spaces. If e-commerce is the surface of economic activities, Product Acquisition is the engineering cycle to build those products to be traded. What makes the matrix different is the new way to realize the product life cycle from an idea or product concept and how to implement a "triple-A" enterprise (Lee, 2003). The Full concept of Participatory Production is originally from "industrial accumulation", which is accumulation of thousands of small factories in a region of the Suwa-Okaya area of Japan (Kita el at, 2008). That concept is further developed in a more distributed manner with SCSE as the physics to perform the same concept with a much higher DoF regardless of geographical factors and the size of participating enterprises in this chapter. Another path of the transformation matrix is the career path. People, as the center of human beings history, are seeking for lifetime, Career Development space to participate in economic activities in varied roles: buyer or service provider, by participating in the virtual enterprise via the Enterprise Life Cycle Management (ELM) concept that will elaborated on later in the chapter.

With the Career Development cycle and ELM coverage, the nested society model in this chapter is a giant, organic system complex to hold economic activities during the evolution process.

\section{Evolution of supply chain management}

It could it be briefly said that the evolution of the SCM discipline is the history of globalization either academically in school or practice in enterprise to manage the more and more fragmented organization worldwide. SCM has been re-defining itself many times: SCM was logistics focused (Houlihan, 1984) and was further extended to cover the flow of goods from supplier through manufacturing to distribution chains all the way to the end user (Christopher, 1992). That original concentration was for Procurement human capital and shifting to performance optimization later to catch up with the new practice in offshoring. From EDI to Internet, the connectivity cost has dropped sharply and the global competition rose up reversely. The increasing cost pressure driving offshoring to gradually 
migrate to outsourcing and the scope of SCM is starting to cross the enterprise boundaries when off-loading the financial burden. That new outsourcing capability enables a new focus on "core competencies" to be more lean in production (Lamming, 1993-1996) and to eliminate waste and non-lean elements along the supply chain (slack, 1995). Only those activities adding competitive advantage can be accepted in a general, long-term sense. Since then, SCM has heavily been extended to multiple disciplines since the 1980s. All the evidences above are supporting the statement about "SCM is catching up with globalization revolution" from time to time.

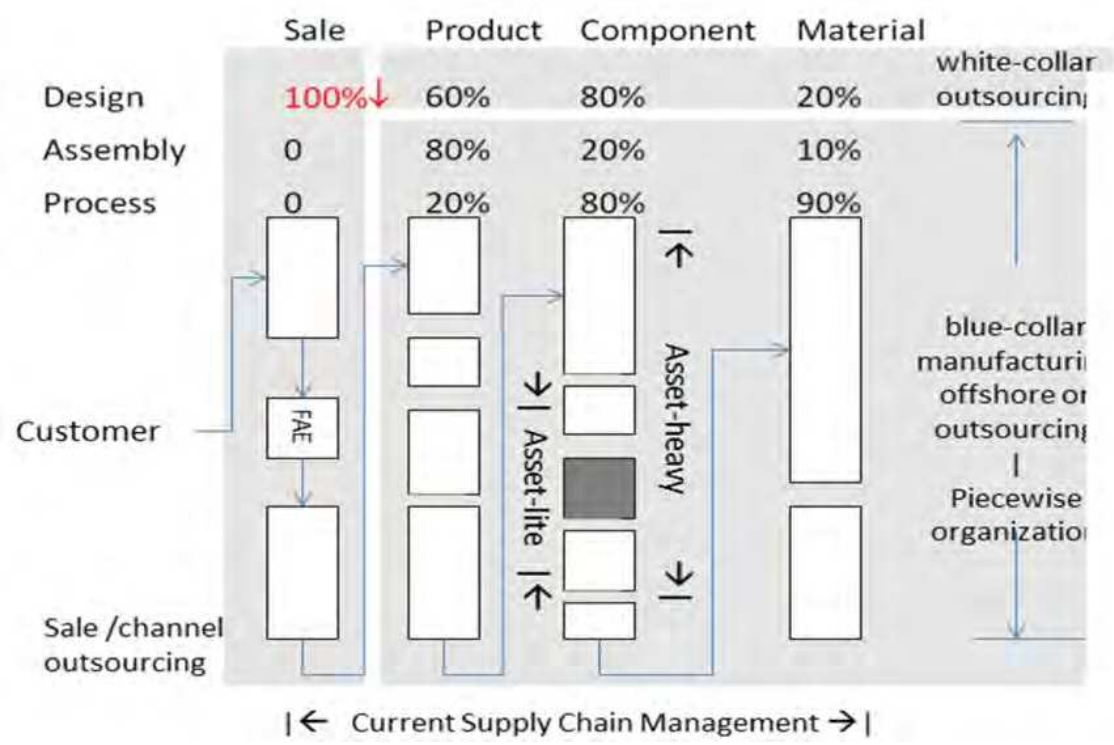

Fig. 3. 3- phases outsourcing toward distributed organization

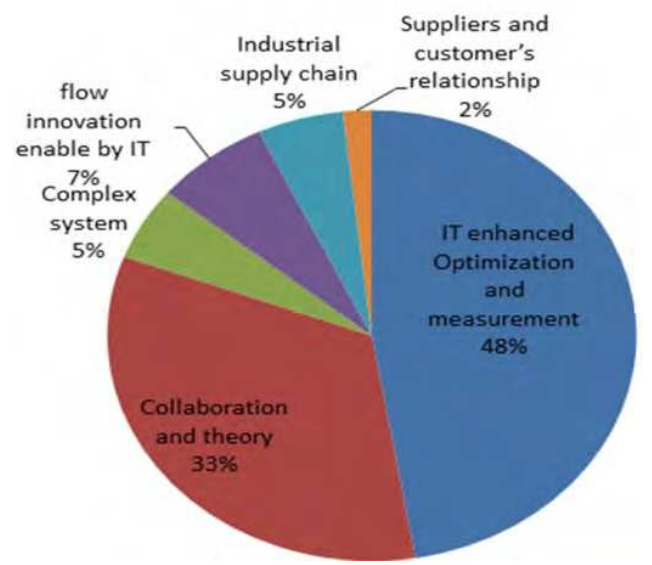

Fig. 4. Statistics of sampling 57 SCM Papers 
Fig 3 is a landscape of demonstrating a typical evolution process of an Integrated Device Manufacturing going toward a highly fragmented, distributed organization from one piece. Downsizing or Strategic Outsourcing is the term to describe it in a negative and a positive way. The progress could be divided into 3 typical phases: (1) blue-collar manufacturing offshore or outsourcing from the 80s to the 90s. (2) White-collar outsourcing overlapping from the 90s to the 00s and (3) fully localized Sale and Field Application Engineering (FAE) forces in the multi-poles economy, overlapping from the 00s to the 10s onward. The world is confirmed to be heading into phase 3 by the Economic Policy Institute (EPI) when the statistics said $1.4 \mathrm{M}$ jobs were created overseas by U.S. companies, compared to $1 \mathrm{M}$ domestically in the year 2010 (Raynor, 2010). More jobs in Sale, FAE, which was treated as "core competencies" in phase 1 and 2, are no longer fully operating in-house but replaced by the localized forces who know the local market better. The new enabler is the fully plannarized channel in e-commerce such as the overcrowded B2B2C market in China (Kai, 2010). In phase 3, both supply and demand are globalized. The "core" of the enterprise is shrinking down to less than $50 \%$ in the headquarters where the mother company resides. In the next decade, what is the next SCM evolution step to manage the high N-factor DoF, both ends outside enterprise is a big challenge.

\subsection{Academia lagging to respond to a changing SCM}

Curiosity keep the cat going, a literature research was conducted by sampling 57 cited papers published since 1996 from the Google Scholar searching engine and the result is summarized in the pie chart in fig 4 . The top category is $48 \%$, all regarding to the traditional SCM care about with the objectives of eliminating waste and improving efficiency by adapting IT tools (K.C. Tan, 2001). The 2nd large category is 33\%, for discovering new natures of post-Internet SCM: developing new theories, and exploring collaboration methodologies etc. The result reflects the SCM evolution is responding positively to the changes hardly but there seems to be not much rock solid results coming out on integrating external organization that crosses the enterprise boundary (Croom, 2000). Only two categories were caught by the eyes and dropped into the radar screen of the desired solution space: seeing the Supply Chain Network a complex system connecting enterprises in largescale industry. They are both 5\% with 6 cases in total: 4 from Automotive, 1 from Construction, and 1 from the Chemistry industry. The statistic is so disappointing in percentage and even a declining trend of SCM papers in quantity was observed. If fig 3 represents the trend of business development then fig 4 is what the academic field response to the need from business was in the last decade. For those executives searching for a high $\mathrm{N}$-factor DoF solution, the result is far from satisfactory, however, it does have a very good, high-level abstract description to the ultimate goal of SCM in layman words: to be a TripleA enterprise: Agility, Adaptability, and Alignment (Lee, 2004). Unfortunately, it still lacks the implementation detail to reach that goal. In order to make that high-level "Triple- $\mathrm{A}$ " business concept be more practically adaptable, the requirements in fig 3 are therefore fatherly transformed into a mechanical 3D model for the value chain integration in fig 5 below. In the research result, Enterprise wants to be "Triple-A" with a high-N factor DoF and size independent on connectivity with partners have to overcome those challenges.

The 3D model reveals that horizontal, vertical, and human capital integration are three orthogonal dimensions, those used to be handled by independent disciplines. The 1st dimension vertically integrated workflow among functions is what the "cascade effects" 


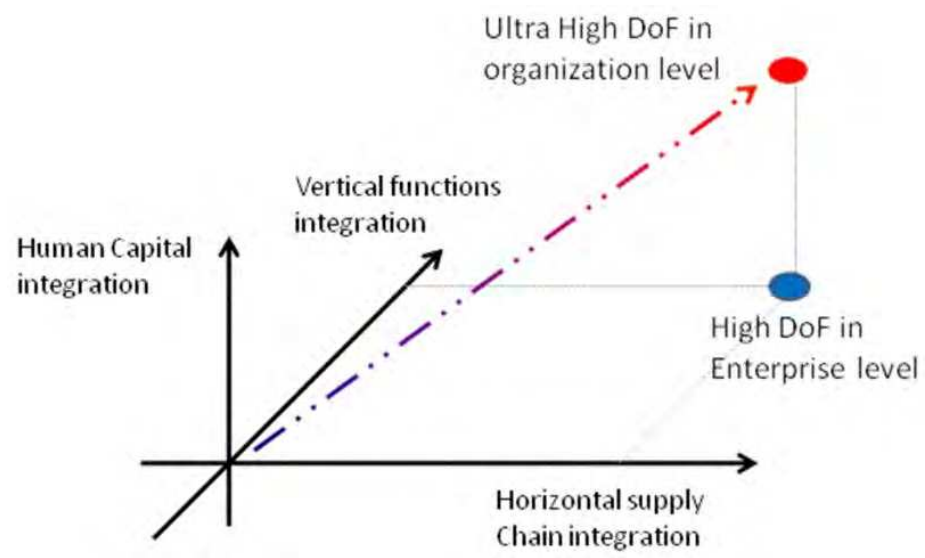

Fig. 5. Simple 3D Model of SCM mechanics for Nested Society

storing in IDM. The 2nd dimension is to make that "cascade efforts" transferrable to a nested enterprises structure. The enterprise archives both dimensions are reaching the high $\mathrm{N}$-Factor virtual enterprise maturity but not in the human capital level. If enterprise can reach the 3rd dimension it reaches another level of DoF taking advantage from the nature of knowledge economy: independent contributor in the form of freelancer or contractor in an on-demand basis. From the asset management point of view, the first 2 dimensions represent more DoF of managing fixed assets and turn fixed assets into a variable cost in the economic sense. The last dimension is representing DoF of flexible organization over flexible business architecture to deal with the business dynamic.

\subsection{Best-in-class enterprises are poor in SCM integration}

Curiosity keeps the cat going continuously. A survey from Aberdeen Research over Process Collaboration in Multi-Enterprise Supply Chains was conducted recently to see what is happening inside the enterprises in the revolution process (Tsai et al, 2009). The result is summarized into the Table 1 below in the "Enterprise" section on the left. The data clearly answer the question why the SCM evolution hit the wall after the decade development in the post Internet era. It has only two " $100 \%$ " appeared which is PLM and ERP in Best-InClass (BIC) enterprise. They are also representing the best practice within the first dimension. However, even in the BIC category, the intra-operation is also suffering difficulty and dropping to $45 \%-75 \%$ when it comes to integrating Engineering activities in MES and Quality engineering activities in the Quality System. The bottom of the table shows those "cascade efforts" under the competitive workflow are not easy to be transferrable when it comes to the 2nd dimension to integrate the functional integration deeply in-house to be horizontally integrated with external resources. It drops dramatically into a single digit from about $8 \%$ and not more than $28 \%$ even in the Best-In-Class enterprise category.

The right side of the Table 1 is further examination the availability and readiness from the first dimension going forward to the 2 nd dimension then to the $3 \mathrm{rd}$ dimension that a virtual enterprise needed for a nested society. The poor result on the right side is making sense when the minimum level of DoF is not reached yet on the left even in the BIG category. 


\begin{tabular}{|c|c|c|c|c|c|c|c|c|c|}
\hline & \multicolumn{6}{|c|}{ Enterprise } & \multirow{2}{*}{\multicolumn{3}{|c|}{$\begin{array}{c}\text { Virtual Enterprise } \\
\text { Enterprise Level Supply Chain } \\
\text { Solution }\end{array}$}} \\
\hline & $\begin{array}{l}\text { BI } \\
\text { C }\end{array}$ & AVG & LAG & BIC & $\begin{array}{c}\mathrm{AV} \\
\mathrm{G}\end{array}$ & $\begin{array}{l}\text { LA } \\
\text { G }\end{array}$ & & & \\
\hline (Intra) & \multicolumn{3}{|c|}{ Quality System (\%) } & \multicolumn{3}{|c|}{ MES (\%) } & $\begin{array}{c}\text { Value } \\
\text { Added 3PL } \\
(\%)\end{array}$ & $\begin{array}{c}\text { VHRO } \\
(\%)\end{array}$ & $\operatorname{ESE}(\%)$ \\
\hline PLM & 75 & 22 & 0 & 100 & 50 & 33 & \multirow{3}{*}{\multicolumn{3}{|c|}{$\begin{array}{l}\text { Operation-Over-The-Net (OOTN) } \\
\text { is Operation Management } \\
\text { Methodology for Supply Chain } \\
\text { Network needs intensive care on } \\
\text { Engineering and Quality } \\
\text { collaboration }\end{array}$}} \\
\hline ISCM & 45 & 43 & 0 & 71 & 65 & 25 & & & \\
\hline ERP & 64 & 38 & 25 & 100 & 74 & 75 & & & \\
\hline (Inter) & \multicolumn{3}{|c|}{$\begin{array}{c}\text { Large Suppliers } \\
(\%)\end{array}$} & \multicolumn{3}{|c|}{ Customers (\%) } & \multicolumn{3}{|c|}{ SME suppliers/partners } \\
\hline $\begin{array}{l}\text { Internal } \\
\text { Process }\end{array}$ & 17 & 13 & 8 & 28 & 16 & 8 & $\begin{array}{l}\text { Don't } \\
\text { know }\end{array}$ & $0 \%$ & $0 \%$ \\
\hline
\end{tabular}

$\mathrm{BIC}=$ Best-in-Class, AVG = Industrial average, LAG =Laggard; MES = Manufacturing Execution System, PLM= Product Life Cycle Management, ISCM = Internal Supply Chain Management, ERP =Enterprise Resource Planning; Inter = Inter-operability, Intra =intra-operability. ELM="Enterprise Lifecycle Management", VHRO=Virtual Human Resource Organization, ESE="Extended Enterprise System Engineering", "SME=Small and Medium Size Enterprise"

Table 1. System to System Integration: Enterprise vs. Virtual Enterprise

\subsection{Further evolution: Massive convergence}

"Connectivity" is the nature of the Internet and it is a new element to human beings' evolution. The literature research and survey have confirmed the evolution both in academia and enterprise are showing disappointed result after 15 years of post-internet evolution in SCM integration. From the result, this chapter is suggested the current ITcentric approach is not working when it is crossing private space boundaries. From the 2 paths in the transformation matrix, in private domain it has to be user-centric and any connectivity between space owners is unique. Therefore, there are three new constraints have to be considered:

- Hybrid-connected as norm for heterogeneous supply network, no one-system-for-all system like Service Oriented Architecture that again basic principle of competitiveness (Porter, 1998).

- User-centric language when implement workflow automation coming to connection oriented application. IT model needs to express in business language, operation languages, and personal development languages that private space owner understand

- Nested social complex must contain all economic activities at the end of digitization process.

Traditional SCM has a much smaller application scope but it has to compile those higher level constraints when SCM is taking more contribution to connect the private spaces within the nested society. The SCSE in this chapter satisfying the PP application requirements is the first set of solution in human history can fulfil all those constraints. The 4 dimensions fusion 
process inside the SCSE has achieved zero disruption operation excellence and evolves since then 2000. It took 7 years to transform the IT-centric languages into operation languages in the 3D model that merge technology management and engineering management with SCM. It works but not well consolidated due to too much disciplines included. In 2007, the system engineering and acquisition cycle was added into the SCM project and it was renamed into SCSE. In about 2009, the project was started confirming the SCSE cannot resolve the SME or freelancer issue and it is not satisfied to be an Enterprise level solution. The research team in Flow Fusion Research Lab (here after as "research team") decided to extend the coverage of the private space from virtual enterprise space only to cover the private personal space as well. After the end point has been fixed, massive convergence around the SCSE model is expected via the iterating process. In the literature research, only $10 \%$ of the statistic is taking similar approach with SCSE approach. When the $10 \%$ minority touchdown first it might or might not trigger immediate massive convergence due to expected high resistance from majority, in reality.

\section{Management constraints and solution space}

The previous section transforms the IT connectivity domain into the $3 \mathrm{D}$ intra-operation domain where there is a language that the management can understand and measure. The 3D model reveals managerial requirements and the solution availability from academics and enterprises from consultant or IT service providers are also explored. This section is to dig out what constraints and decision-making process among executives lead to the gap of the poor SCM integration in Table 1. A pair of bidirectional development paths induced from the 3D model is developed for an ecosystem type of participatory production. That kind of model is suggested to be the solution space for next decade for higher DoF virtual enterprise with a feedback loop.

\subsection{Dark side of top-down decision-making flow}

Executives are normally the core team who are holding the steering wheel to navigate though the challenges from the changing business environments. However, when there is a revolutionary level change and happens so quickly the experiences of the executives might lead the ship to somewhere unknown based on their successful experiences in the past. After reviewing with hundreds of executives, 3 major types of assumptions were commonly found during the decision-making process of dealing with the value chain management.

(1). "Do Best, IT does the Rest": an executive who over simplifies value chain management as a Procurement function in the traditional SCM. To them, anything outside of the enterprise boundary is a purchasing activity and IT tools for productivity to help Procurement process is where they spend the money. That mentality would never consider engineering and quality activities as possibly part of the value chain operation regardless of the complexity of the collaboration in the 3D intra-operation requirements. In general, the over-simplified SCM leads to high quality cost, low responsiveness, and IT gets all the blame as illustrated in the top-right corner in fig 6. On the other hand, IT can easily find excuses to get out such as "just too expensive to implement" or "the IT consultant does not do the job". That 'musical chair' scenario makes no accountability in the entire organization is the most common lesson learned leads to the poor SCM result. In this case, no organization is required to change. 


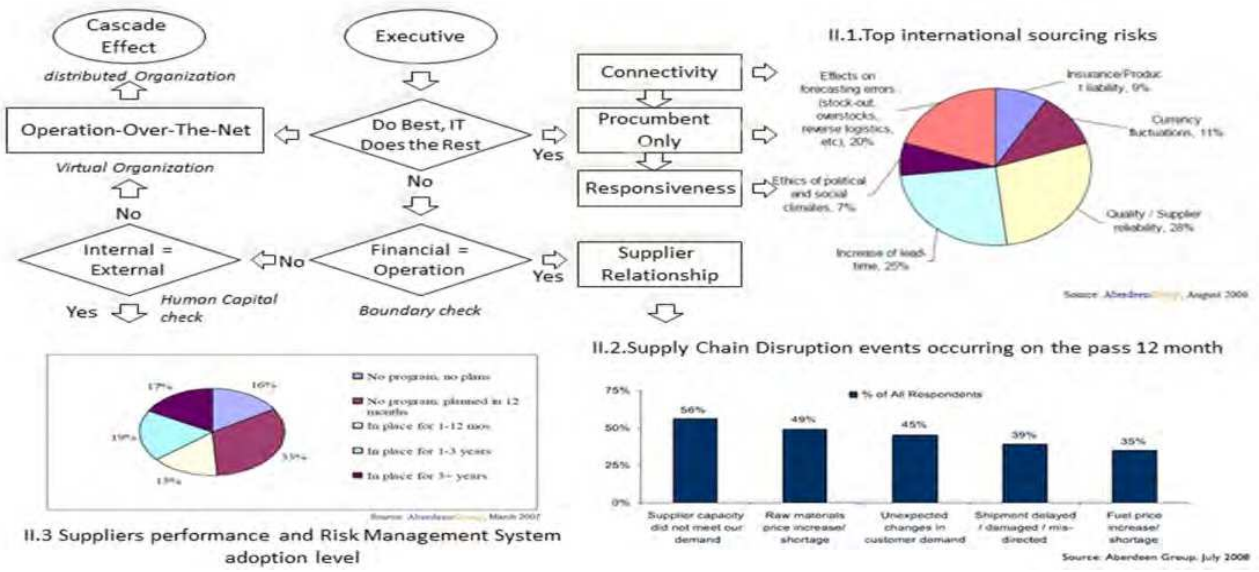

Fig. 6. Mind map of Executive Decision

(2). "Financial Boundary Equal Operation Boundary": There are another group of executives who think there should be organizational change: when anything comes across the company boundary it is business. Therefore the Customer Relationship function and supporting function such as the legal department are needed to support the Procurement closely. In our research, the Customer Relationship organization approach is a great improvement compared to the Procurement mentality. Actually, the concept of putting SCM in the business level is extremely important. For example, asset-heavy industry to adapt the "SWING" model in the enterprise level to optimize asset utilization in the pharmaceutical industry (Pisani, 2006) and semiconductor (Tsai el at, 2008-2009) are very common. Similarly in the LCD-TV industry, leading brand names were increasing outsourcing production to reduce the risk and gain asset flexibility from $28.2 \%$ in 2007 to $41.1 \%$ in 2012, especially in hard economic times reported by iSuppli $(\mathrm{Wu}, 2008)$. Another advantage of pulling the SCM up into a business, strategic level activity is staying alert when a businessman is supervising the Procurement. Unfortunately, it still cannot handle engineering and quality disruption events as is indicated on the bottom-right corner of fig 6 .

(3). "Human Capital is the same in Managing the Internal and the External Organization": There are some executives who knows either going to the Procurement approach or Customer Relationship approach would not resolve the SCM issue in a complicated industry. However, many of them fall into the 3rd common challenge: difficult to find right human capital to manage tasks for an external, distributed organization. Table 2 below summarizes the major discrepancy between human capital for managing the internal and the external organization. The acronym, RAA, standing for Responsibility, Accountability, and Authority is one of the critical setups in SCM similar to the Project Management requirements in System Engineering.

Human capital strategy is an increasing challenge to most executives for managing virtual enterprise. For example, from table 2, the multiple-disciplines integrator who is covering business, engineering, and IT all together, it is almost impossible to find qualified candidates in the job market. Furthermore, the positive overlap culture that most innovative companies embrace internally is also questionable when applying to the supply chain due to the possible business interest conflicts or IP protection concerns under the over-the-distance 


\begin{tabular}{|l|c|c|c|c|c|c|c|}
\hline $\begin{array}{l}\text { Positive } \\
\text { Overlap }\end{array}$ & authority & Talents & Knowledge & Shared & IT systems & $\begin{array}{c}\text { IP } \\
\text { Sharing }\end{array}$ & Teamwork \\
\hline Internal & inhibit & $\begin{array}{c}\text { If due } \\
\text { diligence } \\
\text { required }\end{array}$ & $\begin{array}{c}\text { Better } \\
\text { communication }\end{array}$ & Mental & homogeneous & $\begin{array}{c}\text { Free \& } \\
\text { legal }\end{array}$ & $\begin{array}{c}\text { Face-2- } \\
\text { face }\end{array}$ \\
\hline External & inhibit & $\begin{array}{c}\text { Back-up } \\
\text { contact }\end{array}$ & $\begin{array}{c}\text { Multi- } \\
\text { disciplines } \\
\text { Integrator }\end{array}$ & Profits & heterogeneous & $\begin{array}{c}\text { Need- } \\
\text { to-know }\end{array}$ & $\begin{array}{c}\text { Over } \\
\text { distance }\end{array}$ \\
\hline
\end{tabular}

Table 2. Requirements of human capital requires in Distributed Organization: Internal vs. External

working environment. For the Human Resource department, there are challenges too. For example, in an extreme case, a company in phase 3 is having more than $50 \%$ of its original business outside of its current enterprise boundary. The CEO is now managing less functional departments compared to the executive who is covering SCM function but no employee reports to him. The embarrassing situation is similar for those supply chain integrators. If the human resource is still measuring the pay check, or job grade by head counts under the manager, what salary should the Human Resources pay the super integrator in the supply chain operation that manages $50 \%$ plus of the revenue for the company with no one reporting to him?

\subsection{Paired, bidirectional decision-making flow}

Enterprise pays big dollars to the executive with broad enough knowledge, deep enough insight and knows how to make the right decision. However, those experiences are an advantage but constrains as well when it comes to cutting-edge technology or in a dynamic business environment like today. Sun, CISCO, and Blackberry were great companies and their CEO show incapability to deal with challenges. The research team re-think how to avoid those dark sides of the top-down decision flow to be a real "Triple A" enterprise. The solution here is to borrow a similar approach from the Department of Defense (DoD) back in 1985 while DoD issuing the DoD 4245.7-M standard with lots of templates with best practices for governing the process quality of "TRANSITION FROM DEVELOPMENT TO PRODUCTION". The 3D model is self-explanatory when comes across to multipleenterprises, multiple disciplines but those kind of complicated systems we need a "help

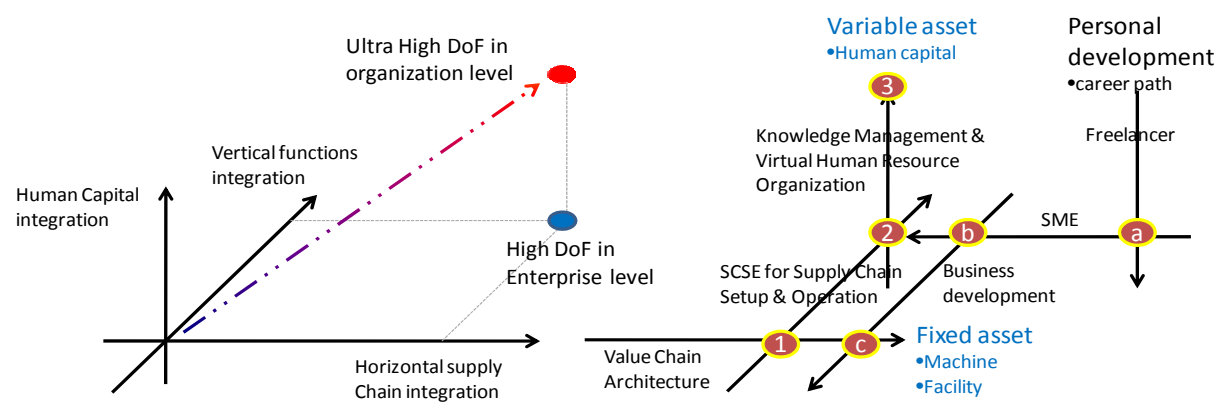

Fig. 7. Bidirectional paths to Enterprise Development and Personal Development within the 3D Model 
menu" to assist. The SCSE itself is adapting the System Engineering framework to carry the best practices in the supply chain and set a boundary of deployment for a new supply chain setup of a new supplier selection and operation onward. The original 3D model on the left in fig 7 is further developed to the right hand side to have paired development paths for a Virtual Enterprise executive.

It is paired paths to form the closed-loop. The top-down path to implement downward and bottom-up path coming backward for the freelancer to participate in the job inside the virtual enterprise activities. For the executive, there are 3 steps to do:

1. Value Chain Architecture: focus on value chain integration for business development to bring in opportunity and revenue. Its focus is on the "Horizontal Supply Chain" dimension to access fixed assets such as machine, facility, and determine the 1: $\mathrm{N}$ ratios, where $\mathrm{N}$ is the financial leverage ratio of the DoF. The financial reference model for that decision making will be discussed in more detail later.

2. SCSE Supply Chain Setup and Operation: When the executive approaches and closes the deal with the ROI he wants, it has assumption of risk such as quality cost and Probability function of risk level, risk exposure etc for a certain $\mathrm{N}$ factor in DoF. An expert of SCSE is helping the executive to negotiating the deal in the business architecture stage and implements the supply Chain setup to mitigate risk and set controls to the risk parameters to be below the assumption in the deal. Otherwise, it is a losing money deal with huge losses since the $\mathrm{N}$ factor is amplifying both the profit and loses as well. The SCSE framework here is a one-stop shopping solution that can handle SME as well from the pair of the Personal development route. That makes the virtual Enterprise size independent.

3. Knowledge Management and Virtual Human Resource Organization (VHRO): Enterprise with a High $\mathrm{N}$ factor in a high DoF model does not have full chain facility therefore holding knowledge and training human capital is a big challenge. For costs concerns and having a goal of not being limited by the knowledge pool internally are the norm in a Virtual Enterprise practice. The VHRO is such an organization structure to assure accumulation of knowledge management with the right human capital in an on-demand basis regardless of the internal or the external human capital pool. The VHRO is connectable to Personal Private Space.

The role of the top-down business development path is quite straight forward but the reverse side of the personal development path might be quite unique.

a. Powered Freelancer: this implies there is a "Personal Private Space" that is holding the career path of the individual be able to perform personal development, and with embedded VHRO to be connectable to virtual enterprise as accessible human capital to the virtual enterprise human capital pool.

b. Powered SME: this implies the "Personal Private Space" is organic and can "grow up" from the individual freelancer continuously to be a business entity as SME infrastructure wise. This SME is also connectable to the Enterprise as part of the Enterprise level SCM solution to the Virtual Enterprise to be size independent. In today's Supply Chain practice, managing SME is a very challenging task in most companies.

c. Business Development: The "Personal Private Space" is growing from freelancer to SME then upward to the large enterprise. When any freelancer comes to this stage it is Virtual Enterprise and his role is changed. The feature to manage the organic growth of 
the freelancer to SME and grow as a virtual enterprise is called Enterprise Life Cycle Management (ELM).

\subsection{Constraints and solution space}

Identifying the root cause is a necessary condition to separate risk from the worry list. Only seeing IT is very easy to get loss where the mind map picture out why most executives in our research cannot get out of the maze when business environments change so dramatically in the IT revolution process. With those understandings of the failure mechanism, Probability of failure, consequence of failure, people can seek a solution objectively to handle the risk. The first things this chapter does is to transform the IT languages in the The3D model that the executives understand and can find people to talk internally via a right sets of requirements in business and operations. The constraints is somewhat the people put it himself therefore limited the solution space himself. To setup right, the virtual Enterprise already was defined as a multiple-enterprise, multiple disciplines, and strong intra-operation dependent system complex. To do it right, it is very risky to rely on a hero to save the company in such a complex system. That is the reason for borrowing the best practices, DoD 4245.7-M type approach enforces the fusion process reference to assure good quality and the paired path provides feasibility of avoiding the dark side of the top-down hierarchy issue. The research team also believes the SCSE solution is an improvement from the DoD approach since they only issues standard, templates, or sophisticated NAVSOP-6071 standard with "trap". However, SCSE is also providing physics, reference models, methodologies, reference IT models, reference facilities etc that with much more tools than the DoD solution by publishing standard only:

- Double path, feedback loop: Not only takes care of the top down process but also the bottom up as well as a pair to assure self-adaptation capacity to dynamic environments.

- Fully empowered life cycle management from freelancer to scalable virtual enterprise: there is an imbalance in power between sizeable enterprise and the freelancer in many aspects from IT to resources. In this SCSE framework a lot of setup is designed to break those barriers and that is what the "take out the IT mask" means to the IT revolution.

The pair enables ecosystem from asymmetric supply chain, symmetric, to participatory production: The research indicates taking out the IT constraints, size independent supply chain environments, and feedback loop are basic mechanisms to the live, organic ecosystem. SCSE frameworks does all and those constraints are mostly gone. The back-to-basic, risk management approach is what the SCSE employing to provide a new level of DoF of virtual enterprise. The new improved model to allow SCSE connectable to private personal development space has escalated the solution space of SCSE into the full solution space toward the ultimate goal of the nested society. It will be elaborated more detail in later chapter. Overall, user-centric language and feedback loop is helping out the executive walking out of the mind map without getting lose.

\section{Virtual enterprise composition process}

The composition process of virtual enterprise is an alignment-adaptation-alignment process from the enterprise level to the individual. The 3 step top-down path for the executives are representing the sequence of setting up a value chain in virtual enterprise form crossing one dimension to the others. The horizontal supply Chain integration sets the network 
topology, cost structure, and flexibility of the supply chain. The vertical functions integration, both internal and external seamlessly, set the organizational structure and architecture of the distributed operation over the selected topology. Since most of the fixed assets required for the target product such as machine availability, facility, and capability have been configured in the first stage, the second stage is how to make those "cascade efforts" vertically transferrable, or adaptable to the new supply chain configuration horizontally. The last step is how to retain that piecewise knowledge among the distributed organizations into one set of integrated system organically and independent of the changing supply chain network topology later.

\section{Nomenclature}

ROI = Return of Investment

Asset Ratio $=$ actual assert $\%$ invested for $100 \%$ revenue

$N=\mathrm{N}$ factor of $\mathrm{DoF}, \mathrm{N}=1 /$ Assert ratio

$S=$ Sensitivity Function of Value Chain

$D=$ Delinquency

$Q=$ Quality function in value chain

$\mathrm{T}=$ Topology of the value chain including how to cut the chain into pieces and where to cut

Inv $_{i}=$ Inventory in Stage $i$

Out $_{i}=$ Capacity Output in Stage $i$

$P_{i}=$ Price in Stage $i$

$P_{\text {Market }}=$ Price in Market

$$
\begin{gathered}
\text { ROI }=\operatorname{Max} \operatorname{ROI}(\mathrm{N}, \mathrm{S})-\operatorname{Min}(\mathrm{Q}, \mathrm{S}, \mathrm{D}, \mathrm{P}) \\
\mathrm{S}(\mathrm{T}, \operatorname{Inv}, \mathrm{Q})=\Delta \mathrm{ROI} / \Delta \mathrm{D}(\%) \\
\operatorname{Inv}_{\mathrm{i}} \cap \operatorname{Inv}_{\mathrm{j}} \equiv \emptyset, \forall \mathrm{i}, \mathrm{j} \\
\text { Total Investment }=\min \sum_{\mathrm{i}} \operatorname{Inv}_{\mathrm{i}}=\mathrm{a} \\
\text { Total Output }=\max \sum_{\mathrm{i}} \text { Out }_{\mathrm{i}} / \mathrm{a}=\mathrm{b} \\
\text { Price Risk Margin }=\max \left(\mathrm{P}_{\text {market } \left.-\sum_{\mathrm{i}} \mathrm{P}_{\mathrm{i}}\right)}\right. \\
\text { Return Risk Margin }=\max \left(\sum_{\mathrm{i}} \mathrm{P}_{\mathrm{i}}-\sum_{\mathrm{i}} \operatorname{Inv}_{\mathrm{i}}\right)
\end{gathered}
$$

\subsection{Value chain architecting principle}

The first step of the composition process is decomposition of the value chain and pick up partners. The definition of "Value Chain Architecture" in the top-down implementation process can be briefly illustrated by the 2-steps in fig 8 technically.

Step 1: $\mathrm{N}$ factor analysis and Sensitivity Check: Enterprise can simply plot the graphic by remodelling the asset ratio against the $\mathrm{ROI}(\mathrm{N}, \mathrm{S})$ in equation (1) as shown on the graphic plot on the top-left corner. Asset-heavy is used usually to describe a company that has a high asset ratio in a capital intensive industry. In the graphic plot example, an asset-heavy with $100 \%$ asset-ratio is losing money anyway. However, in the simulation, if the executive sells off assets to be $50 \%$ asset-lite and outsources the rest, it is up from around $-10 \%$ to $+20-30 \%$ magically without any real improvement. If it is up to $25 \%$ asset-lite ( $75 \%$ outsourced), it is 
up to $45-75 \%$ ROI. The executive also needs to check sensitive S(T,Inv,Q) in the equation (2) of the value chain architecture about the appropriated topology, possible critical paths, right inventory policy, quality strategy, and liability payment terms dependent. An example is illustrated on the top-right corner of fig 8 about how sensitive the ROI is vs. the asset ratio.

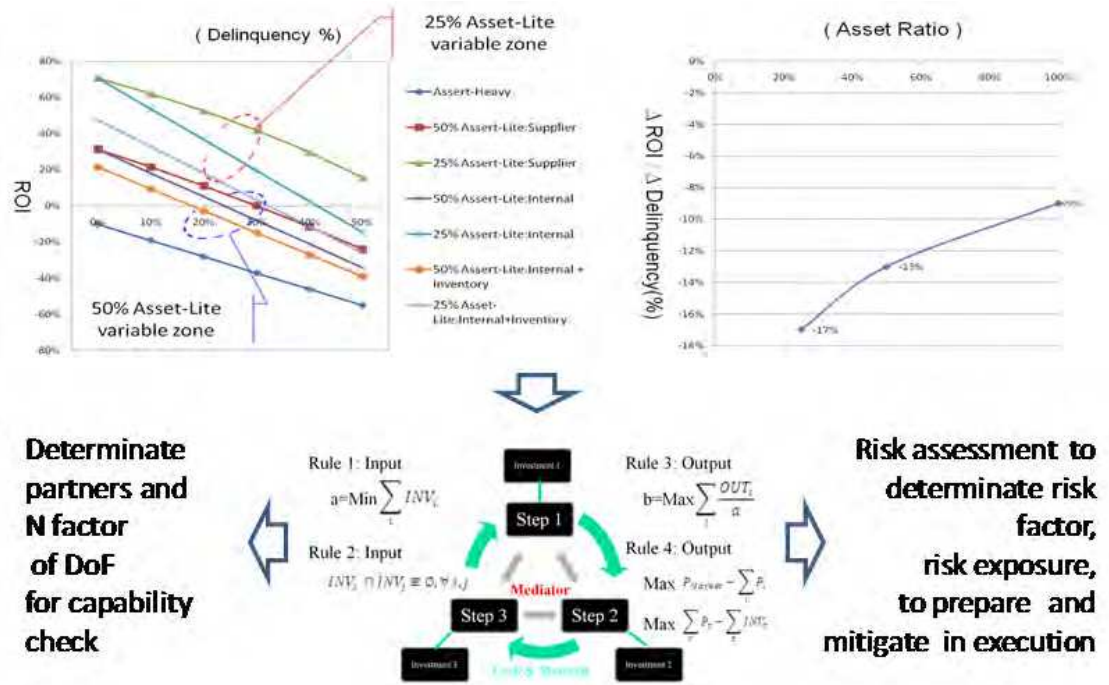

Fig. 8. Value Chain Architecture determination process

This is a first step that the CEO needs to work with the CFO to determine the characteristic of a virtual chain setup with an advantage and a thorough risk assessment. Those are all preparations that any enterprise ought to perform before going to the next step and must be done before making a decision of the next step, making a right decision.

Step 2: Value Partners Alignment: Once the $\mathrm{N}$ factor is identified and Sensitive is well understood, the value chain integrator, usually is the product owner, is going to assemble the chain. Before the firmed market opportunity and business model has been verified, there are usually 5 basic rules from equation (3) - (7) to follow as shown in the bottom of fig 8 . Equation (3) is to avoid interest conflicts among the chain from the beginning to assure longterm stability. Equation (4) and (5) are straight forward on investment and output capacity. Equation (5) and (6) are risk factors to avoid negative ROI and the year taken to ROI.

The output of step 2 might be varied from step 1 and the chain needs to be recalculated and re-optimized spontaneously. In step 2, the value chain integrator must be a mediator to assure fairness among partners and the Profits and losses are proportionally coming back to each stage of the chain for a long-term relationship.

\subsection{Quick adaptation process of supply chain setup}

As stated, the minds map of the executive determines the consequence of a supply chain setup: either a trading in procurement route or a contract setup in a business relationship route in general. In this chapter, the SCSE solution with paired paths in the 3D model space cover the engineering route with quickly deploying and handling engineering capability. Since the SCSE is performing based on a unique Business Gateway Model (BGM) 
architecture, therefore connectivity is assumed (Tsai and $\mathrm{Lu}, 2011$ ). This chapter is employing a 3C model representing "Connect", "Contain", and "Collaborate" in fig 9 to implement the quick adaptable process.

1. Connect: the Low Level Logistics (LLL) provides superior agility on horizontal connectivity and superior takes ownership later on differentiated workflow automation if necessary. In the experimental data, the connectivity cost is defined in the equation (8) with a great year-on-year cost reduction roadmap

2. Contain: The Virtual Enterprise Space on top of LLL infrastructure is a KNOWLEDGE CONTAINER design which is allows supply chain users to determine what is contained in the supply chain to make it functional (Tsai and $\mathrm{Lu}, 2011$ ). Inside the container, it has 5 elements (Material, Machine, Methodology, Metrology, and Man) in the terms of a distributed production composition (Tsai and Wang, 2004) and 3 segregated flows (Production, knowledge, human capital) in terms of workflow management in Participatory Production.

3. Collaborate: With basic connectivity and the right container to start with, it can start the Supply Chain Operation, organizational alignment and perform the Operation-OverThe-Net process for continuous improvement in parallel (Tsai and el at, 2009). After positive engagement and up to a certain maturity, the buyer starts to exit and transform ownership to the supplier and focus on activities about supply chain robustness.

\section{Nomenclature}

$y=$ the year from project started

$C C_{i}=$ the Connectivity Cost in Supply Chain node I, in thousand, USD

$O E=$ Organizational Efficiency, multiple factor to productivity for manual operation

$$
\begin{gathered}
\mathrm{CC}_{\mathrm{i}}(\mathrm{y})=89.78 \ln (\mathrm{y})+196.52<2 \\
\mathrm{OE}(\mathrm{y})=2.3811 \mathrm{e}^{0.231 \mathrm{y}}>12
\end{gathered}
$$

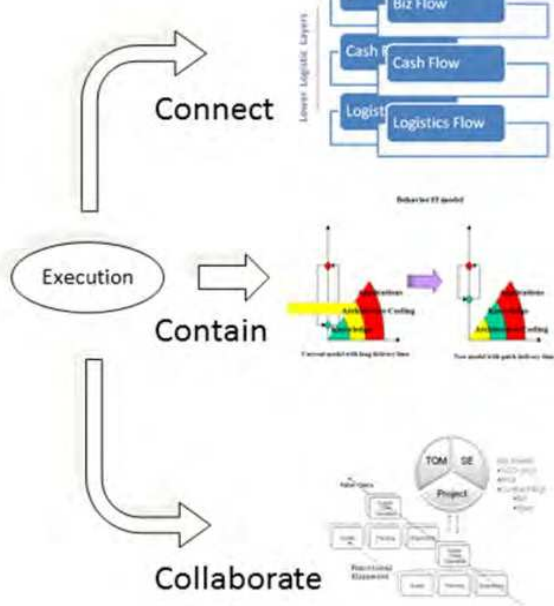

Fig. 9. The 3C QUICK Adaptation process

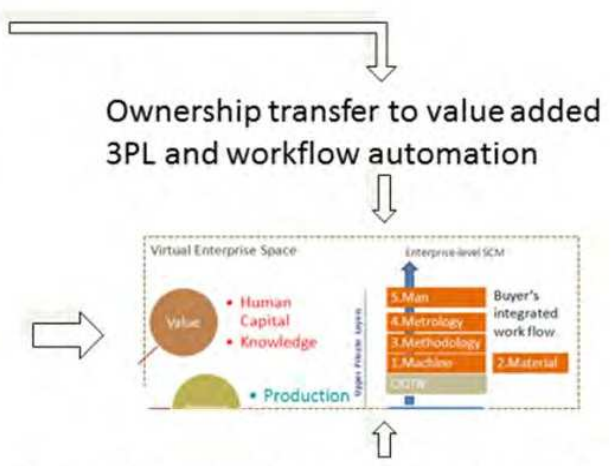

Ownership transfer to suppliers via OOTN Model for continue improvement 
The 3C adaptation process is the simplest way among today's exiting methodologies available in a complicated supply chain complex market and it has been designed in the possible faults during the execution. For example, the rapid connectivity and the financial services from the LLL service provider is to avoid using IT as an excuse and possible cash flow discontinuity especially in a high $\mathrm{N}$ factor value chain. The KNOWLEDGE CONTAINER design is providing complete methodology set and tool set for flexibility and feasibility to cover broad industry applications. The last " $\mathrm{C}$ " Collaboration is to avoid another excuse from operation remotely to the distributed organization is not feasible. The 3C adaptation is designed to transfer "cascade efforts" from a competitive, complicated industry from an integrated entity to a fully segmented supply chain such as Participatory Production.

Next section will explore more from "Contain" to "Collaborate" in SCSE to build and manage supply chain for Participatory Production. This is a concurrent, learning organization but the learning curve is expected to be quick. The boundary of the learning organization is set at equation (9) from the experimental data in the past 15 years.

\subsection{Management and communication among silos network}

All the "Triple-A" setups above are the bright sides and certainly dark side or "weakness" as well in any design:

SCSE is a preventive design, a design for Supply Chain, but still, a passive structure in the implementation level to execute deployment, same as all methodologies

The goal is to transform the central organization from the complicated supply chain complex into a simplified, e-commerce network that has its dark side: a Silos network. SCSE architecture is embedded with aligned, constructed with a feedback loop, and sealed with an ecosystem but that is still a big potential threat to react to changes in a Silos society.

The BGM also has some very unique features in design due to being part of the nested society:

- The BGM is sharing the same skeleton with the Personal Development Space (Tsai and $\mathrm{Lu}, 2011$ ) in order to cover the full range of partners from freelancer to large enterprises. That provides incentive on being a self-starter for their career goal.

- The Business Gateway is capable of connecting to individual professionals to form a virtual team as external human capital to support business in an on-demand basis

All those factors in pros and cons lead to the same special setup of Self-aligned Knowledge Management (KM) method. To operate a Virtual Enterprise with 50\% more assets outside the company boundary is very difficult to communicate, and deploy policy. The boundary for the communication efficiency is set at equation (10).

\section{Nomenclature}

$I E=$ number of Incoming Events, per day

$C R=$ Compression Ratio

$C E=$ Communication efficiency, in number of articles, events, or news

$$
\mathrm{CE}=\mathrm{IE} / \mathrm{CR}<20 / \text { day }
$$

The excremental KM facility, which is a communality holding freelancer and SME for the nested society, is reported to performing a more than $3 x$ Compression Ratio in articles compression efficiency. The fusion chamber is compressing multiple sources from academic, 
enterprise presses, and valuable news and all merged under the knowledge model from the book "The world is flat" (Tsai, Lu and el at, 2011). When adapting the similar strategy in the private enterprise network passively the silos are capable of knowing the market changes in real time with less than 10 mins reading time a day for a quick review.

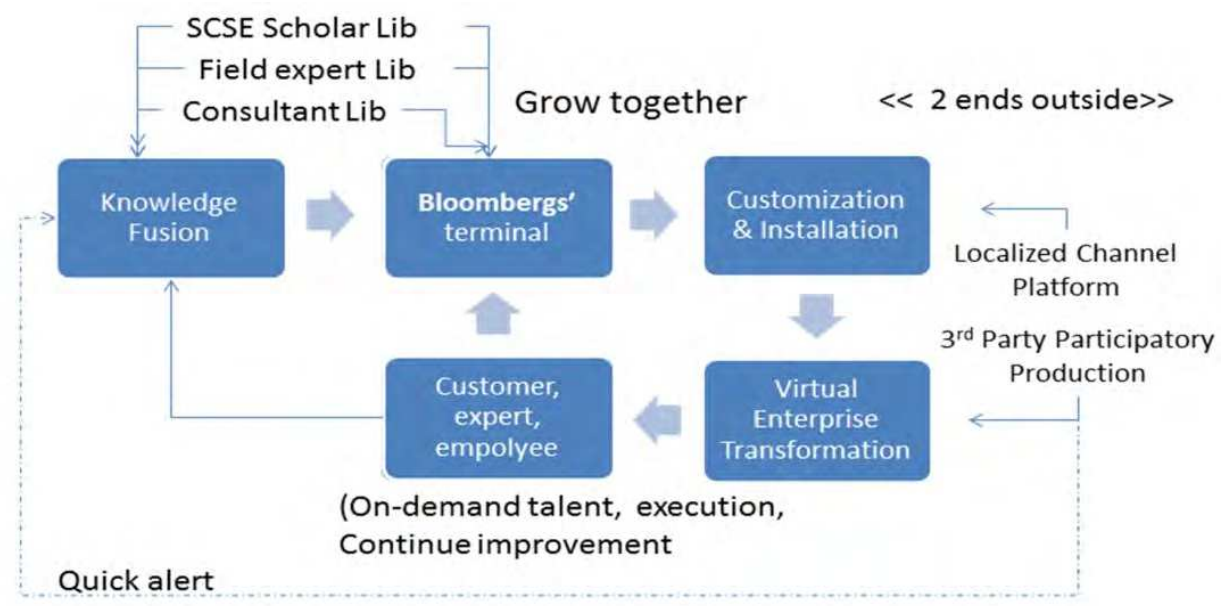

Fig. 10. Self-Aligned Knowledge Management Structure in Virtual Enterprise

With the infrastructure, management is capable of deploying news and deployment to the community for all silos in a segregated supply network actively. If using the article fusion, composition, and automatic dispatch capability further, any member in the private community can actively share an idea of how to improve or react to the changing, dynamic business environments. Reference architecture of adapting such a self-aligned KM features is illustrated in fig 10 below. The uniqueness of this design is that it is including the changing world and dynamic business environment as part of the KM coverage but not limited to the Technology inside the supply chain. It is a full spectrums scan from academic, field expertise, to dynamic news and feedback though a compressed, high-efficient KM network to help communication inside the silos network and align among them. To deal with challenges, knowledge is the first element to have.

The self-aligned architecture in fig 10 is one of the supporting infrastructures of nested society architecture to enable a human capital network outsourcing in BGM by pulling out the human capital as an independent workflow in the virtual enterprise. It is an open structure connecting to the outside community which is designed for the Customer-Centric Organization to busting out silos in the distributed organization for effective collaboration and capability incubation of human capital (Gulati, 2007). The unique design to decouple human capital flow from the production flow in the 3D model is not only to set the KM free from the operational workflow but also to set free the talent management as well. The scope of the paired paths for managing the virtual enterprise dynamics is covering a full acquisition cycle and fragmented value chain, the demand of human capital with appropriated knowledge is varied along the cycle and among the product line as well. It is required to be setup on an on-demand basis and operate like fig 10 to be capable to align with changing, customer-centric business environments. 


\subsection{Full application scope in acquisition cycle}

This section is peeling the onion one more layer down about how to implement SCSE to architecting the value chain, quickly adapt, setup the supply chain, and what KM the silos network is needed to retain competiveness in a dynamic business environments. This section also implies a "Triple- $A$ " enterprise could be an alignment-adaptation-alignment process to reach its Agility in the best practice sense. This composition process is generic to the full acquisition cycle covering all milestones. It is maturity level independent when aligning value chain, performing $3 \mathrm{C}$ adaptation process, and conducting $\mathrm{KM}$ among the Silos network. The SCSE model has considered the maturity dependency therefore it is a loosely coupled framework in KNOWLEDGE CONTAINER design. The framework is generic to all kinds of engineering activities are contained inside the CONTAINER as long as it is within the design boundary. From next section, it is one more layer down in the headachy and it is more specific to operation setup and operation management required to mass production at post milestone C. For a specific Maturity Model for Milestone A and B will not be covered in this chapter as stated in the earlier section on the coverage hierarchy chart. That will be part of the risk management topic in New Product life Cycle Management.

\section{SCSE for supply chain setup and operation for milestone C}

The pervious section is generic rules, best practices to covers the full acquisition cycle such that anytime an executive can apply that framework to architecting his value chain in early stage of the acquisition cycle. Once the maturity level is up to be in milestone $C$, it needs detail, thorough setup of the Production and Sustainment stage of the acquisition cycle. That implies the Product and Process Technology baseline is available for Technology Transfer from the development site into the receive site during the adaptation process. This chapter will assume effective Technology Transfer methodology to cover the availability of the $5 \mathrm{M}$ elements (Material, Machine, Methodology, Metrology, and Man) is available. A brief discussion about who needs the SCSE model and following with next 5 big steps sequentially a to build and delivery a SCM solution about the "Contain" and "Collaborate" mentioned in the previous section during the adaptation process.

\subsection{Who needs the SCSE model}

In early traditional SCM it is mostly single tier operation in term of visibility during the order fulfilment or MRP process. When more and more outsourcing activities in the industry, multiple stages supply chain is not uncommon in end product holding companies such as cell phone giants Nokia, Apple etc. Those are strictly SCM players and they are micro-managing multiple-tiers supply chain. However, it is still retained in procurement level and it is not common to include the engineering in regular practice. Therefore the most popular reference standard SCOR model from Supply Chain Council and protocol RosettaNet are not included that. There are many reasons to keep the Process Technology in-house and most important one is technical challenges about intra-operationability because engineering integration is heavily involved in Process Technology industry such as semiconductor, and chemical process factory. In a raising industry, that barrier is competitive advantage to keep inside but once the industrial cycle is matured. That barrier becomes a major show stopper for who wants to go assert-lite especially to those capital intensive industries. 
Therefore for Industry who has complicated collaboration intensive activities in house and consider moving out partial to full production outside but still keeping the core competency inside, they need SCSE. Those engineering intensive activities are not the procurement or customer relationship department can handle. It has complicated Supply Chain Delivery Process in fig 11 in pervious section and coming out with multiple functions organization other than Procurement and Customer Relationship functions. How an enterprise connects the external resources into internal organization is also enterprise dependent. In general, it has a delegated External Manufacturing Organization to handle external activities under the same enterprise umbrella from Quality System, Risk Management, to Product life Cycle management.

\subsection{Setup and operation deployment}

In SCSE architecture, the process of setting up, deployment, and building operation are very similar with adapting a requirement engineering process in System Engineering. There will be one requirement to all suppliers in abstract level for one supply chain but it will come to different local specification technically and in operation during the allocation process. It has 3 requirement allocation paths in parallel: Technology Transfer, Logistics setup, and the final Operation deployment respectively for any particular supplier as shown on the top portion of fig 11 to establish production baseline and reach operation settlement.

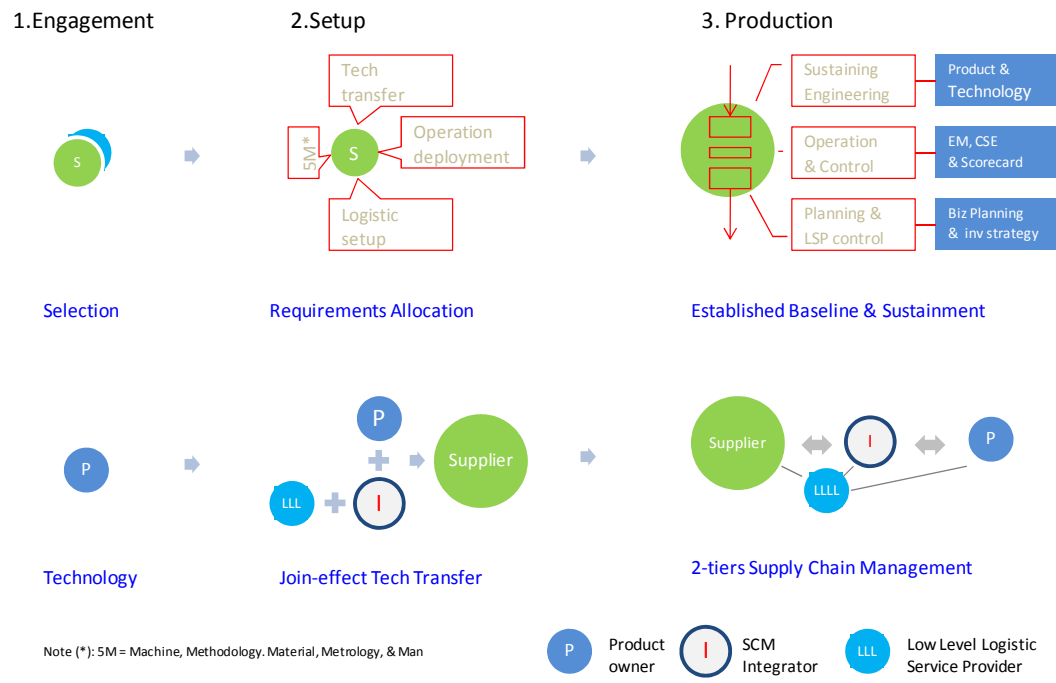

Fig. 11. Supply Chain Delivery Process for Participatory Production

The lower portion of fig 11 is the ownership transformation process among the parties and role changing schema among the Participatory Production setup. The SCM integrator is the "mediator" to put all the puzzles together, balance the interest conflicts according to the boundary conditions set in equation (1)-(7), and becoming the professional Supply Chain Manager of the newly formed supply chain. The LLL service provider is a new concept in BGM model to pull out Logistic flow, Cash flow, commerce flow from the overall Supply Chain Operation Complex for system complexity reduction purpose (Tsai and $\mathrm{Lu}, 2011$ ). 
The IT model and assumption behind will be briefly covered in the Section: System Scalability and Model Spectrum.

\subsection{Dual branch vee model for supply chain network}

Network nature is new characters of post-Internet virtual enterprise from traditional SCM. In order to make the enterprise to be connectable to the Emmentaler-like structure for Nested Society complex, there 2 major steps to make it works in our experimental facilities in the last decade.

\subsubsection{Be network ready and compatible in term of elements}

In this chapter, the Enterprise System Engineering has been modified into a new Enterprise System Engineering (ESE) framework (Tsai, 2008) by adding Strategic outsourcing layer "Value Network" into the four well-known frameworks CIMOSA, PERA, GIM, and GERAM as illustrated in fig 12 below (Tsai, 2008). The model adapts the Classification Schema in ESE framework, which had defined 16 enterprise elements to create "View" of enterprise architecture (Oscar 2004). With that additional strategic outsourcing layer, enterprise is eligible to be network-ready as illustrated in fig 12 how buyer splits the elements categories to form branches in network as part of the nested structure (Rebovich 2006). The new "Value Network" layer under Enterprise element layer has four elements to support architecting value chain: Value Position, Supply Network, Asset Allocation, and Control. With the new layer and elements, activities setting up new supplier in fig 11 can be implemented by cell combination such as Work-Supply-Network-Requirements-PlanQuality for technology transfer. The cell combination of Resources -Value PositionStrategy-Analysis-Benefit can represent strategic decision.

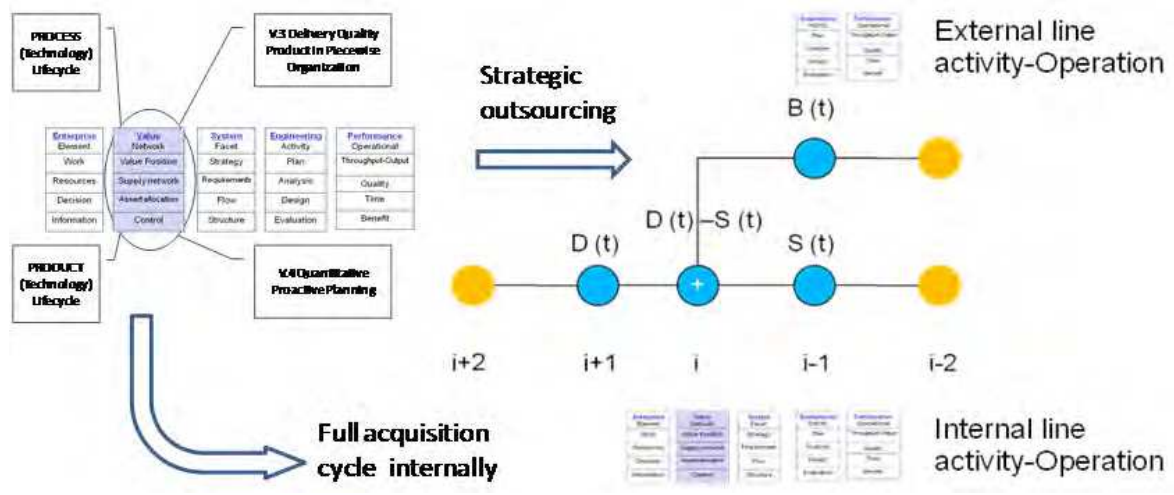

Fig. 12. Network-Ready Enterprise Activities

Figure 12 demonstrates an example of putting the Activity-Operation combination into one internal production line and one external production line on top of the cascaded supply network. That represents the cell combination Work-Supply-Network-RequirementsActivity-Operation of the extended ESE framework, which are now broken down into two segments: "Work-Supply Network-Requirements" and "Activity-Operation." The former is resident in the buyer enterprise and the later is duplicated into multiple copies: one copy stays in internal production line and one copy sends to external production line. Right side 
of fig 12 is the simple $i+2$ visibility supply network model for SWING model when applying strategic outsourcing. Equation (11) is the Summation Rule where $B(t)_{i}$ is the allocation or alternative sources from the mismatch between Supply $S(t)_{i}$ and Demand $D(t)_{i}$.

\section{Nomenclature}

Node $\mathrm{i}=$ Node $\mathrm{i}$ in supply network

$D(t)_{i}=$ Demand time series in node $i$

$S(t)_{i}=$ Supply time series in node $i$

$B(t)_{i}=$ Backup Supply time series in node $i$

Output $(t)_{0}=$ the time series of Product Output at the root, which is the start of the value chain.

$t_{f}=$ forecast visibility up to $i+2$ nodes

$\mathrm{C}_{\mathrm{i}}=$ Cycle time in node $i$

$Y_{i}=$ Process yield of node $i$

$$
\begin{gathered}
\sum \mathrm{D}(\mathrm{t})_{\mathrm{i}}-\sum \mathrm{S}(\mathrm{t})_{\mathrm{i}}=\sum \mathrm{B}(\mathrm{t})_{\mathrm{i}}, \mathrm{t} \leq 0 \\
\sum \mathrm{D}(\mathrm{t})_{\mathrm{i}}+\sum \mathrm{S}(\mathrm{t})_{\mathrm{i}}=0, \mathrm{t} \geq \mathrm{t}_{\mathrm{f}} \\
\text { Output }(\mathrm{t})_{0}=\sum_{\mathrm{i}}\left(\mathrm{Y}_{\mathrm{i}} * \mathrm{~S}(\mathrm{t})_{\mathrm{i}} * \sum_{0}^{\mathrm{i}} \mathrm{C}_{\mathrm{i}}\right)
\end{gathered}
$$

The ESE structure on the left is enabling the network capability of an enterprise and it is also ready for operation activities including the V.4 "Delivery Quality Production in Piecewise Organization" and V.5 "Quantitative Proactive Planning" that will be discussed in later sections. Equation (12) is the Proactive Planning Rule which is necessary in SCSE setup for better visibility for fast response on sourcing allocation and enabler to cascade the sequential value chain. Therefore all nodes can cascade to a value chain for Value Chain Planning for total output planning in equation (13). The equation (11) - (13) are the basic supply chain network rules for each product in SCSE designed for network-ready enterprise.

\subsubsection{Branch Dual Vee (BDVee) model for supply chain network branch building}

In this chapter, the master of the value chain has to be network-ready and perform the Branch building from node to node to response to the business demand. There are two basic elements about the BDVee Model: Branch and network. In SCSE, regardless to internal or external resource in value chain, all are stationary node (geographically location), and branch is the line to connect two nodes together. Breaking up the connection between two nodes is removing a branch from the network and the topology of connecting nodes into a network determinate the robustness, surge capability of a supply network. Only when the supply network satisfied equations (1)-(7) to be mutually beneficial that is a value network for long-term supply chain relationship. The BDVee model is focus on managing life cycle of a branch with 2-layer structure as illustrated in fig 13.

\subsubsection{Build a new branch in network}

The top portion of the chart layout is the life cycle of a branch. The down $\mathrm{V}$ on the left is evaluating and setting up (or growing) a new branch:

- Evaluation: select target node from resources pool according to availability, technology roadmap, quality system, capacity roadmap, financial stability, business alignment, etc.

- Setup baseline: build setup task team on both sides to transfer process baseline and ownership to target node. Qualify product baseline and build remote operation, etc. 
- Ramp preparation: put up ramp-up plan and facilitate resources and activities to support from engineering, manufacturing, logistics, IT, to capacity support, etc. for remote operation.

On the right side of the Vee diagram moving upward, that is simply a realization process of a new, physical branch in supply network. It finally exits when business is misaligned or business value diminished:

- Ramp: deliver the ramp-up plan committed and see whether the smoothness of operation, product yield, and reliability are meeting mass production criteria. Correct all necessaries before going to next mass production stage.

- Mass production: delivery cycle and focus on volume, price reduction, and services.

- Exit: branch disconnection procedure either triggered by business misalignment (price, value chain conflicted, business interests conflicted, etc.) or deliverables misconduct (delivery, quality, service, etc.), or product consolidation due to end of product life cycle.

The 1st layer of the BDVee Model in Fig 13 is also called a network Vee, or Branch Vee to connect nodes into a supply chain network. This layer is focus on the activities when the branch is building.

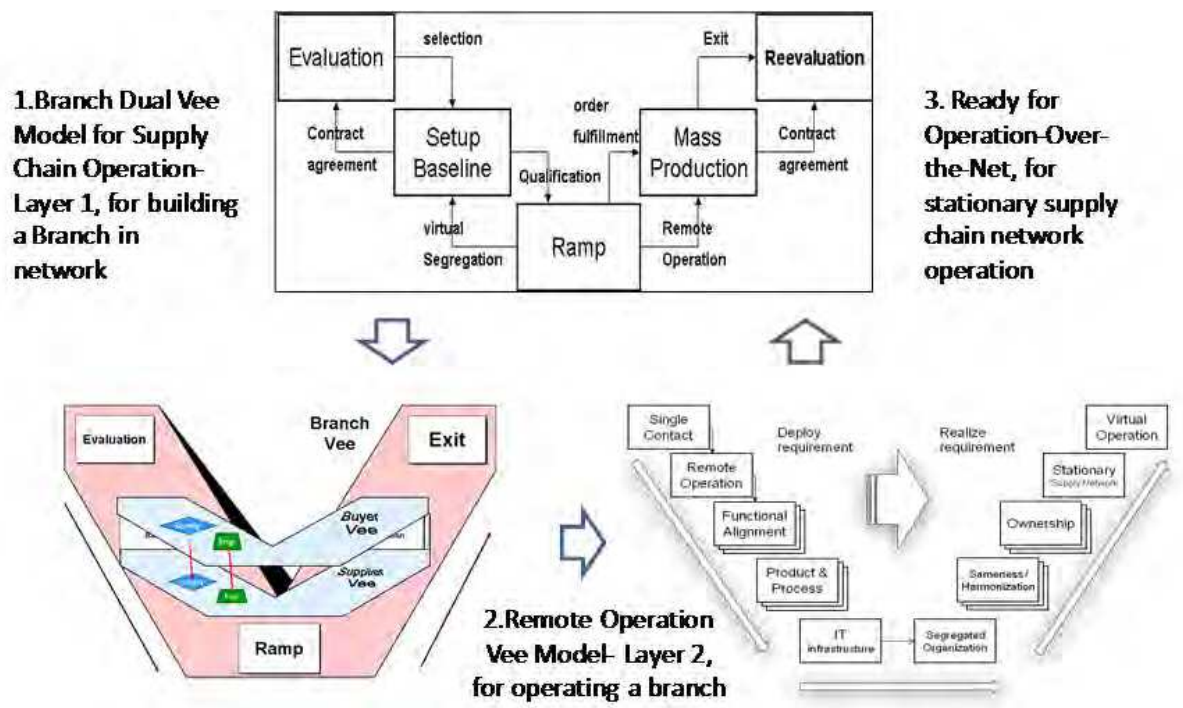

Fig. 13. Building a 2-layers Brach Dual Vee Model for Supply China Network

\subsubsection{Operating a branch remotely}

The 2nd layer is setting up an organization to operate the supplier node remotely and effectively. It crosses over the "Setup Baseline" and "Mass Production" blocks in the 1st level. The "Remote Operation Vee Model (ROVee Model)" conducts all managerial activities to operate appropriately and correctly through the product life cycle.

The ROVee Model has a double-layers structure to connect the two buyer-and-supplier nodes together and it is also a platform to operate remotely after the initial setup. The double layers are identical to connect functional departments of both organizations in two 
companies. The pair also called "Total Quality Management (TQM) pair" where it states the principle to compile the TQM requirements while setting up a remote operation. The detail of ROVee Model structure is shown as the bottom-right corner in Fig 13. The left hand side of the Vee model is the deploying requirements of building a remote operation.

- Single contact policy: organizational structure required to guarantee $100 \%$ information integrity to support Peer-2-Peer operation remotely. The output is "Virtual Operation."

- Remote operation requirements: activities matrix to operate two remote companies seamlessly. The output is "Stationary Supply Network".

- Functional alignment requirements: transfer ownership to at least one functional department (Collaborative Planning). The output is "Ownership" in supplier.

- Collaborative Quality: quality ownership transfer (Tsai and Wang, 2004).

- Collaborative Engineering: engineering department ownership transfer.

- Collaborative Planning: transfer quality and engineering sensitivity to planning department (Tsai et al. 2004-2008).

- Product and process requirements: select one of the options to produce product from supplier. The output is "Sameness / Harmonization" for product/process.

- Turn-key Solution: product in EDA/DFM tools only and all process technologies are provided by supplier, no inter-stage process dependency among value chain.

- Technology Transfer: product owner has its own process baseline and transfers to supplier. Buyer only wants capacity from supplier, strong inter-stage process dependency among value chain.

- Process R \&D: buyer working with process technology provides to develop customer specific process for customer. Strong inter-stage process dependency and heavy communication among value chain.

- IT requirements: IT setup to meet fundamental requirement for "segregated organization."

Both "functional alignment" and "product and process" requirements in the deployment cycle have options. This design represents a very important nature of supply network: every branch could be different in term of product, process and therefore difficulty level to build a branch in the supply network. Some of them will require 3rd level Vee model such as the three functional alignments (Tsai et al. 2004-08) and Technology Transfer. The flexible dimension horizontally in department alignment and flexible dimension vertically in difficulty level are critical features of the BDVee Model to be backward compatible to current scientific management practice and widely adaptable to other industries. The Quality Vee Model in section 5 "Delivery Quality Production in Piecewise Organization" is a very common functional Vee that most enterprise will come to implement when building a new branch.

\subsection{Quantitative Planning Model for quality}

A Quantitative Planning Model was created to support supply network in fig 12 under the BDVee model. Based on that model, here we define the Inventory Time $\operatorname{Series}_{\ln } \mathrm{V}_{\mathrm{t}}(\mathrm{i}, \mathrm{j})$, Supply Time seriesS $\mathrm{t}_{\mathrm{t}}(\mathrm{i}, \mathrm{j})$, Return Material Acceptance time seriesRMA $\mathrm{A}_{\mathrm{t}}(\mathrm{i}, \mathrm{j})$, and Supply Cost time series $\mathrm{SC}_{\mathrm{t}}(\mathrm{i}, \mathrm{j})$ from supplier $\mathrm{j}[2]$,

\section{Nomenclature}

$i=$ the current buyer

$j=$ the supplier $j$ 
$t_{l}(j)=$ remaining available time for supply from supplier $j$ at supply stage $l$

$l=$ the supply stage $l$, including the inventory (stage 0 ),

$W I_{t}(i, j, l)=W I P$ quantity for buyer $i$ at supplier $j$ at stage $l$ at time $t$

$\operatorname{pr}\left(i, j, t_{l}\right)=$ purchasing request function

$p\left(i, j, t_{l}\right)=$ probability function of

$q c\left(i, j, t_{l}\right)=$ Cost function

$n_{t}(j)=$ number of WIP stages at supplier $j$ at time $t$

$m_{t}(j)=$ number of planned periods for new start at supplier $j$ at time $t$

$$
\begin{gathered}
\text { Quality Return }=\sum_{\mathrm{l}} \operatorname{pr}_{\mathrm{t}}\left(\mathrm{i}, \mathrm{j}, \mathrm{t}_{\mathrm{l}}\right) \cdot \operatorname{RMA}\left(\mathrm{i}, \mathrm{j}, \mathrm{t}_{\mathrm{l}}\right) \\
I N V_{t}(i, j)=I N V_{0}(i, j)+\sum_{l} p r_{t}\left(i, j, t_{l}\right) \cdot \operatorname{RMA}\left(i, j, t_{l}\right) \\
S_{t}\left(i, j, t_{l}\right)=\left\{\begin{array}{c}
\operatorname{IN} V_{t}(i, j), t_{l}=t_{0} \\
\operatorname{pr}\left(i, j, t_{l}\right) \cdot p\left(i, j, t_{l}\right), t_{1} \leq t_{l} \leq t_{p o} \\
S_{t}\left(j, j+1, t_{l}\right), t_{l} \geq t_{p o}
\end{array}\right.
\end{gathered}
$$

where $\operatorname{pr}\left(i, j, t_{l}\right)$ and $p\left(i, j, t_{l}\right)$ are

$$
\begin{gathered}
\operatorname{pr}\left(i, j, t_{l}\right)=\left\{\begin{array}{cl}
P O, & t_{0} \leq t_{l} \leq t_{p o} \\
0, & \text { elsewhere }
\end{array}\right. \\
p\left(i, j, t_{l}\right)=\left\{\begin{array}{c}
\frac{S H\left\{i, j, t_{l}\right\}}{P O}, t_{0} \leq t_{l} \leq t_{p o} \\
0, \text { elsewhere }
\end{array}\right.
\end{gathered}
$$

If a quality event happens at buyer's production line, the Buyer Quality Event should be estimated which is defined as

$$
\begin{gathered}
B Q E C_{t}(i, j)= \\
\sum_{t_{l}} W I P_{t}\left(i, i, t_{l}\right) \cdot \operatorname{Cost}\left(i, i, t_{l}\right)+\sum_{t_{l}=t_{0}}^{t_{e n g}} W_{t}\left(i, i, t_{l}\right) \cdot \operatorname{Cost}\left(i, i, t_{l}\right)+\sum_{t_{l}=t_{0}}^{t_{s t o p}}\left\{S C_{t}\left(i, j, t_{l}\right)\right\} \\
t_{c t}+t_{F I F O}=\sum_{\text {all stages }} c t_{i} \\
\left\{S C_{t}\left(i, j, t_{l}\right)\right\}=\sum_{l}^{p_{t}} q c\left(i, j, t_{l}\right) \cdot \operatorname{pr}\left(i, j, t_{l}\right)
\end{gathered}
$$

where

$$
q c\left(i, j, t_{l}\right)=\left\{\begin{array}{c}
P_{j}, t_{l}=t_{0} \\
\operatorname{Cost}(i, j), t_{1} \in T_{1} \\
P_{0}, t_{1} \in T_{2} \\
0, t_{l} \geq t_{p o}
\end{array}\right.
$$

Eq. (p.1)-(p.9) provide basic quantitative model for planning which are related to quality event. Eq. (p.1)-(p.2) are inventory level due to possible quality event and Eq. (p.6) is what the buyer wants to eliminate. How this Quality System Vee Model contributes to the quality cost will be discussed in next section.

\subsection{Be a segregated, efficient network organization}

In this chapter, building a stationary supply chain needs a very efficient communication system since organization is located worldwide and has to work like under the same roof to 
claim the "geographically independent advantage". The Segregated Network Organization design is another critical feature besides the single-contact policy mentioned in the BDVee model during the realization process. Fig 14 is showing the major evolution steps to archive that goal to build cascaded, segregated supply chain architecture. In order to build a fast switching, fast response supply network, it has two elements to adjust: the node itself and communication paths between nodes in value chain. This section is to discuss the network aspect of the requirements of building an efficient supply network formation.

First, in regular organization, customer (or sale) department and procurement department are separated as shown on the top-left corner of Figure 14. Between them is Operation. In this study, the structure of the C-O-P has been modified into a new structure to combine "C\&P" and put " $\mathrm{O}$ " perpendicular to the "C\&P". In SCSE architecture, the Business Planning that facing Customer(C) and Procurement(P) Planning that facing Suppliers are combined into a single function unit to reduce system complexity. In network aspect, the supply network is continuing to evolve to a new level of Node structure as shown on the right side of fig 14 .
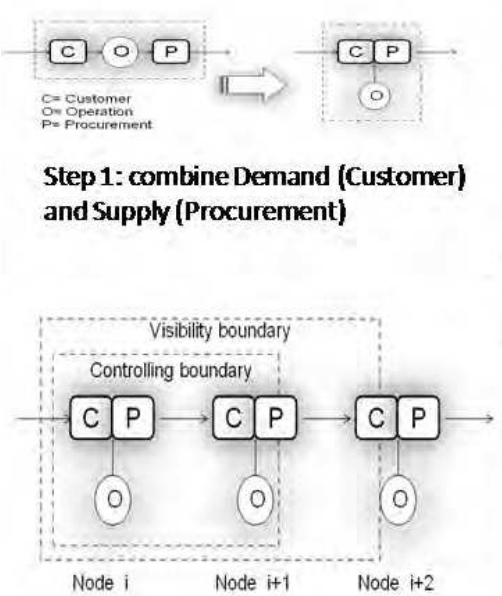

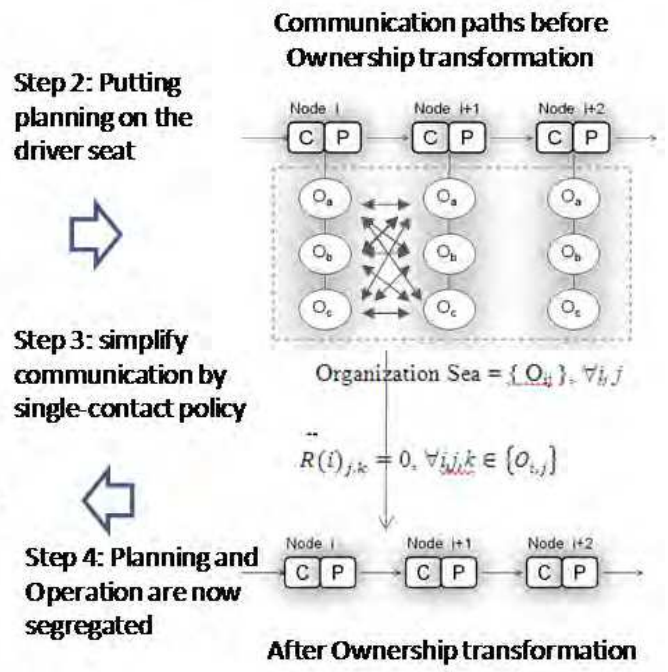

Communication paths before

Organization Sea $=\left\{\mathrm{O}_{4 j}\right\} ; \forall, j$

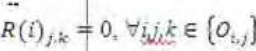

After Ownership transformation

Fig. 14. Planning Driven, high-efficient and segregated network organization

To put planning in the driver seat it has to segregate the operation and planning. Segregation is not equivalent to separation since Segregation is a platform concept. In a Segregated Network Organization actually everything are connected but just deeply buried into the system and not noticeable to every end user. The boundary of segregation is defined in equation (16)-(17) below. In a generic supply network, the communication in the Organization Sea can be expressed by equation (14) and (15).

\section{Nomenclature}

$\mathrm{O}_{\mathrm{i}, \mathrm{j}}=$ Organization $\mathrm{j}$ in Node $i$

$\mathrm{P}(\mathrm{i})_{\mathrm{j}, \mathrm{k}}=$ Communication path between organization $j$ and $k$ in node $i$

$\mathrm{R}(\mathrm{i})_{\mathrm{j}, \mathrm{k}}=$ Communication path between organization $j$ in node $i$ and organization $k$ in node $i+1$ 
Organization Sea $=\{$ Oij $\}, \forall i, j$

$$
\begin{aligned}
\text { Communication Set }= & \left\{\sum_{\mathrm{i}} \mathrm{P}(\mathrm{i})_{\mathrm{j}, \mathrm{k}}, \sum_{\mathrm{i}} \mathrm{R}(\mathrm{i})_{\mathrm{j}, \mathrm{k}}\right\} \\
& \mathrm{R}(\mathrm{i})_{\mathrm{j}, \mathrm{k}} \gg \mathrm{P}(\mathrm{i})_{\mathrm{j}, \mathrm{k}} \forall \mathrm{i}, \mathrm{j}, \mathrm{k}
\end{aligned}
$$

After the segregation step shown on the right side of fig 14, equation (16) becomes the condition below. Subtitle equation (16) into (14) and get (17)

$$
\begin{gathered}
\mathrm{R}(\mathrm{i})_{\mathrm{j}, \mathrm{k}}=0, \forall \mathrm{i}, \mathrm{j}, \mathrm{k} \in\left\{\mathrm{O}_{\mathrm{i}, \mathrm{j}}\right\} \\
\text { Communication Set }=\left\{\sum_{\mathrm{i}} \mathrm{P}(\mathrm{i})_{\mathrm{j}, \mathrm{k}}\right\}
\end{gathered}
$$

After the virtual segregation condition is met. The complicated supply chain complex is now highly simplified into the i+2 network on the left-bottom corner of fig 14 . With the segregation and extended visibility, nodes can be cascaded into value chain by the overlapped +2 visibility and perform value chain planning. For Operation, it is working segregated on engineering and quality activities that will be discussed more detail in later section.

\subsection{Planning-centric, organic supply chain}

This section is layout the 4 important reengineering areas to be a virtual enterprise from our best practice field research: (1) be network-ready intrinsically to add the "Value Network" elements into the ESE framework; (2) know how to build a network branch by applying the 2-layers BDVee model; (3) Build quantitative planning model; and (3) To set up segregated Network Organization to reduce complexity hence high-efficient organization in communication. Thos are major steps to build a fast responds, fast switching, from nodes to branch, and cascades the branches into value chain for stationary supply chain network.

Comparing the decision-making path in the executive mind map in fig 6, this section gives the essential set up methodology and mathematic model to build supply chain in network aspect. The steps here are completed re-organization to simplify the decision making loop must shorter by combining business planning and production planning to make responsive supply chain therefore agility. The mathematic model with right elements connecting to different functional department such as engineering, quality engineering in a segregated network is a very special design to deal with volatile market. The "Planning in the driving seat" concept is very different from the Procurement-Centric or Customer Relationship Centric approach in the executive mind map but customer-centric or demand-centric. The IT therefore connects to all elements in the supply chain from end customer to each level of suppliers to response to volatile market organically. "Organic" is a more advanced and suitable to "Agility" in organization aspect because of the human-centric concept to managing the dynamic market. In a post-milestone $C$ supply chain, Planning is the center with minimum communication path to customer, business decision from executive, suppliers, and now engineering and quality. Since network layer is the e-commence layer in BMG model it is also designed to be backward compatible to SCOR model.

\section{Quality vee model for piecewise organization}

In SCSE architecture, the BDVee Model is an open architecture for completing Supply Chain Network building in network aspect and this section comes to further functional layer on 
operation step. Operation is about to mitigate quality risk and compile goal and schedule, it is business specific. Although the BDVee model saying functional level Vee is optional. The Quality is clearly playing a very critical role in the Participatory Production. In SCSE, Quality department in supplier is redefined to replace the on-site representative of buyer. Quality Vee model in this section, is a reference model do that job to eliminate hidden quality cost inside the piecewise organization in supply network. In virtual Enterprise, the $\mathrm{N}$ factor of high DoF borrowing from the financial leverage concept is a multiplier factor to profit and it is also a multiplier factor to lose as well. Therefore the quality cost is the number one risk that a virtual enterprise needs to eliminate (Aberdeen, 2006).

\subsection{Repairing broken links in piecewise organization}

In most virtual enterprise application, when the quality auditor comes to audit the quality system, they often find the process is somewhat broken due to outsourcing. In a piecewise organization, the basic traceability is hard to maintain and the quality deployment is tuned into business alignment which falls into contract management category. What makes it worse is that, when a quality alert is raised by an end customer, it is hard to locate who is responsible for the issue quickly. In fact, such quality control problem has long been there waiting for the right time to emerge. Quality cost or financial punishment is always a lagging indicator to outsourcing. In the past decade, the quality issues were not emphasized enough by customers either because of the overwhelming low price or alternative choices. But once when the price reduction is stall, or the market is dominated by one supplier or single region, the quality issues are escalated. For example, DELL's service quality represents the former and China's toy safety recalls represent the latter case. In most case, buyer sends on-site representative just for "watching". In SCSE, Quality Vee is a framework to transfer the ownership as shown on the left side of Fig 15 for right accountability. It is a Convergence Cycle of transferring ownership between companies.
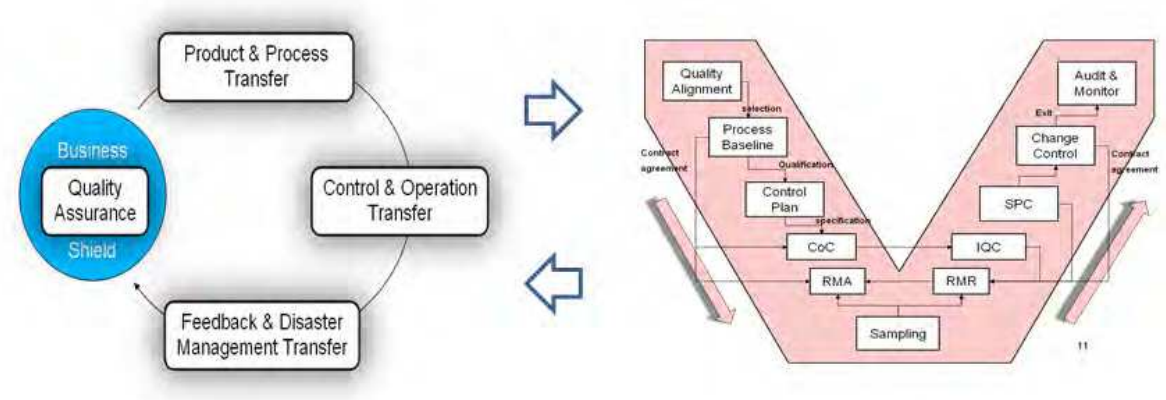

Fig. 15. Quality System Alignment and Quality Vee Model to Transfer ownership to Suppplier

Since SCSE is employing the TQM concept when building the BDVee Model for a new branch. In reality, both buyer and supplier are having complete, efficient and functional organization and they do not need a new organization to supervise them but a way to distribute ownership thoroughly and a way to collaborate seamlessly, just like in TQM. In fig 15, is showing the Quality Vee Model is a tool to perform functional alignment in Quality 
System of both ends. In quality control, proactive approach is the best practice to eliminate quality disruption event before it actually happens:

- Product and Process Transfer: install proactive quality indicators in production line at supplier side by applying product sameness and process harmonization principles among suppliers.

- Control and Operation Transfer: install effective control plan in supplier with preinstalled lesson learned; activate effective remote operation.

- Feedback and disaster management transfer: install mini Business Management System (BMS) as virtual Operation core and integrate supplier's BMS to buyer's overall disaster management.

- Business shield: engineers working with colleagues internally now has methodology and principle references working with counterpart externally to compile the ownership transformation

After the ownership transfer, the external supplier became an extended organization of the buyer but works as if an integrated, internal organization with no additional overhead. If taking semiconductor industry as a worst scenario in supply chain operation, this system engineering approach model can be simplified to apply to many industries.

\subsection{Quality Vee (QSVee) model}

The detail of the QSVee model is shown on the right side of fig 15 with three major parts: (a) deployment cycle on the left, (b) realization cycle on the right, and (c) planning involvement cycle at the bottom. The deployment cycle down the Vee is breaking down into four blocks:

- Quality Alignment: quality manual, coverage, and beyond.

- Process Baseline: how the product is being made (process) and what is going to residue (product).

- Control Plan: what defect level and process capability are allowed during the fabrication process.

- Quality of Compliance (CoC): specification to outgoing product quality attached to supply contract.

After the deployment cycle there is a realization cycle up the Vee on the other side of the QSVee:

- Incoming Quality Control (IQC): counterpart of CoC in buyer as double gate, lagging index.

- Static Process Control (SPC): critical portion of control plan review by virtual BMS, concurrent quality index.

- Change Control: governing change process by constitutional "Baseline Document", also control virtual BMS.

- Audit \& Monitor: internal and external audit to assure QSVee is compiling Quality System of buyer and supplier, a connection window to existing Quality System and organization.

Parts (a) and (b) manage the Quality System rebuild process to connect two entities and to transfer responsibility from buyer to supplier. Applying those two parts into a piecewise organization can get the same quality result as if working with internal organization (Tsai and Wang, 2004). If considering parts (a) and (b) only, QSVee is a result of modeling the Collaborative Quality Protocol in a system engineering approach. Part (c), however, is a further improvement by connecting Quality system to the Planning system: 
- $\quad$ Return Material Request (RMR) / Return Material Acceptance (RMA): RMA is part of the SCOR model but a lagging step. To include Planning in QSVee is to improve planning sensitivity and to transfer ownership in mass production.

- Sampling: a sampling plan to control inventory quality is essential to reduce overall risk and quality cost.

The "Planning Involvement cycle" enables the planning to become the center of quality activity in a matured production line as illustrated in fig 14. This new findings in our case study makes the supply chain operation model more effective and efficient. More explanation will be illustrated after the quantitative model.

\subsection{Prevent quality disruption}

The pervious section explains structure of QSVee and alignment steps to install the Quality System that repairs the piecewise organization. This section is presenting how to measure the quality performance of this model and how to validate the QSVee model to assure it is a right setup. The effectiveness of the model will be demonstrated following the sequence in the "Convergence Cycle"

\subsubsection{Product and process transfer}

The deployment V of the QSVee Model is to assure the product sameness by transferring process baseline to the supplier, implementing effective control plan, and governing process harmonization. Taking a process specification with LSL, USL, $\sigma, T, \mu$, and the process capability $\mathrm{C}_{\mathrm{pm}}$ as below (Chan el at, 1988),

\section{Nomenclature}

LSL $=$ Lower Specification Limit

USL = Upper Specification Limit

$\sigma=$ sigma of distribution

$\mu=X$ bar of distribution

$\mathrm{T}=$ Target of process specification

$$
\mathrm{C}_{\mathrm{pm}}=\frac{|\mathrm{USL}-\mathrm{LSL}|}{6\left\{\sigma^{2}+(\mu-)^{2}\right\}^{1 / 2}}
$$

Eq. (10) is for a single product line. For multiple production lines,

$$
\sigma^{\prime}=\sqrt{\sigma_{1}^{2}+\sigma_{2}^{2}+\cdots \cdot \sigma_{\mathrm{n}}^{2}}
$$

where $\sigma_{1}, \sigma_{2}, \ldots \sigma_{\mathrm{n}}$ are sigmaare from different lines. If $\sigma_{1}, \sigma_{2}, \ldots \sigma_{\mathrm{n}}$ are equal, Eq. (p.11) can be rewritten as for any $\sigma_{\mathrm{x}}$

$$
\sigma_{\mathrm{x}}=\sqrt{\frac{\sigma^{2}}{\mathrm{n}}}
$$

While adapting the "copy-exactly technology" transfer methodology in setup stage [3], the newly added production line is independent of internal or external suppliers if and only if Eq. (p.11.1) is hold for all suppliers in order to hold the same process capability in Eq. (p.10). The continuous driving on process capability improvement by transferring ownership to supplier production line can drive Eq. (p.1) to 


$$
\begin{gathered}
\text { Quality Return }= \\
\sum_{\mathrm{l}} \mathrm{pr}_{\mathrm{t}}\left(\mathrm{i}, \mathrm{j}, \mathrm{t}_{\mathrm{l}}\right) \cdot \operatorname{RMA}\left(\mathrm{i}, \mathrm{j}, \mathrm{t}_{\mathrm{l}}\right) \cong 0
\end{gathered}
$$

The item $\operatorname{RMA}\left(\mathrm{i}, \mathrm{j}, \mathrm{t}_{\mathrm{l}}\right) \cong 0$ is coming from outliner of single event. Eq. (p.2) can also be rewritten as

$$
\operatorname{INV}_{\mathrm{t}}(\mathrm{i}, \mathrm{j}) \cong \operatorname{INV}_{0}(\mathrm{i}, \mathrm{j})
$$

Eq. (p.2.1) is equivalent to assuming that the production line is zero quality risk or the external line is equivalent to the internal line in terms of quality. The challenge is the $1 / \sqrt{n}$ factor in Eq. (p.11.1). It implies that a supply array is not easy to maintain the capability.

\subsubsection{Control and operation transfer}

Eq. (p.10)-(p.11.1) and (p.2.1) would not hold long if Control and driving forces are not consistently in place and driving. In the realization Vee of the QSVeel, IQC, SPC, Change Control are all control systems installed to remotely control the supplier line to assure that the quality will be hold. Be more aggressively to protect buyer, those control systems are all designed to eliminate the possibility of receiving defected products from supplier, so that Eq. (p.6) can be rewritten as

$$
\operatorname{BQEC}_{t}(\mathrm{i}, \mathrm{j})=\operatorname{INV}_{\mathrm{t}}(\mathrm{i}, \mathrm{j}) \cdot \mathrm{P}_{\mathrm{j}}+\sum_{\mathrm{t}_{1}=\mathrm{t}_{0}}^{\mathrm{t}_{\mathrm{stop}}}\left\{\mathrm{SC}_{\mathrm{t}}\left(\mathrm{i}, \mathrm{j}, \mathrm{t}_{\mathrm{l}}\right)\right\}
$$

Eq. (p.6.1) demonstrates that an effective realization $V$ can quarantine that the defected material from defected supplier line will not affect buyer's production line and the defect problem can be detected at early time such that planner can react proactively. The quality cost is on the supplier side and the supply disruption is covered by the tolerance design of the supply network at no cost (Tsai and Yun, 2008). In our case study, supplier loves buyer to deploy QSVee since it minimizes overall quality cost and it sustains supply continuity.

\subsubsection{Planning as quality gate keeper}

The Planning involvement cycle at the bottom of the Quality System Vee Model that put planning in the driver seat is a very neat design found in this case study. In a piecewise organization like supply chain, engineering and quality engineering are only involved during the supplier setup and disappear after qualification. However, in B2B activity, Planning and logistics operations are the real and first-hand operations to compile quantity moving along the supply network.

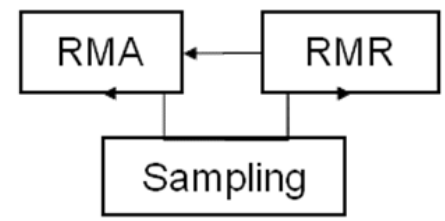

Fig. 16. Planning activities in Functional Vee Model

Fig. 16 is the bottom portion of the Functional Vee Model in Fig 15. The RMR and RMA involvement is to enforce planning has same sensitivity with engineering and quality engineering. For an unexpected quality event, if Eq. (p.2.1) cannot hold and Eq. (p.6.1) also 
cannot quarantine the infected material, infection starts in buyer's production line, and the quality cost will dramatically shot up to Eq. (p.6) with longer quality discovery time in Eq. (p.7). While Planning takes ownership in inventory management and requires supplier to perform sampling by using material start time at supplier, planner can load those sampling material onto the production line sweeping through buyer's line instead of FIFO strategy. The action assures infected line can be detected in minimum cycle time. The ownership also enhances planning to take immediate action to enforce $t_{\text {eng }}=0$ such that $\sum_{t_{1}=t_{0}}^{t_{\text {eng }}} \operatorname{WIP}_{t}\left(i, j, t_{l}\right)$. $\mathrm{P}_{\mathrm{j}} \cong 0$ and Eq. (p.6) can be reduced to

$$
\operatorname{BQEC}_{\mathrm{t}}(\mathrm{i}, \mathrm{j})=\sum_{\mathrm{t}_{\mathrm{l}}} \operatorname{WIP}_{\mathrm{t}}\left(\mathrm{i}, \mathrm{i}, \mathrm{t}_{\mathrm{l}}\right) \cdot \mathrm{P}_{\mathrm{j}}+\sum_{\mathrm{t}_{\mathrm{l}}=\mathrm{t}_{0}}^{\mathrm{t}_{\mathrm{stop}}}\left\{\mathrm{SC}_{\mathrm{t}}\left(\mathrm{i}, \mathrm{j}, \mathrm{t}_{\mathrm{l}}\right)\right\}
$$

The quick action from planning reduces the maximum quality cost in buyer product line to $\sum_{\mathrm{t}_{1}} \mathrm{WIP}_{\mathrm{t}}\left(\mathrm{i}, \mathrm{i}, \mathrm{t}_{\mathrm{l}}\right) \cdot \mathrm{P}_{\mathrm{j}}$. Planning in this quality event also takes immediate action to minimize quality $\operatorname{cost} \sum_{\mathrm{t}_{\mathrm{l}}=\mathrm{t}_{0}}^{\mathrm{t}_{\text {stop }}}\left\{\mathrm{SC}_{\mathrm{t}}\left(\mathrm{i}, \mathrm{j}, \mathrm{t}_{\mathrm{l}}\right)\right\}$ on supplier side and inventory $\operatorname{cost} \mathrm{INV}_{\mathrm{t}}(\mathrm{i}, \mathrm{j}) \cdot \mathrm{P}_{\mathrm{j}}$ on buyer side as well. Since planning is in driver seat, immediate action also takes place to fill the customer's demand using alternative supply sources to satisfy customer. In supply chain management, planning should be always the one in the driver seat even in terms of quality control.

\subsubsection{Change control and baseline control}

Fig. 17 is the state diagram of a change control process before and after applying QSVee between two companies.

Let's define process time of an engineering change $t_{\text {engr }}$,

$$
\mathrm{t}_{\text {engr }}=\sum_{\mathrm{i}} \sum_{\mathrm{j}}\left(\mathrm{S}_{\mathrm{ij}}+\mathrm{R}_{\mathrm{ij}}\right)+\sum_{\mathrm{i}} \sum_{\mathrm{j}}\left(\mathrm{BS}_{\mathrm{ij}}+\mathrm{BR}_{\mathrm{ij}}\right)
$$

where S, and R are time of status change internally, and BS and BR are time of status change externally by going through buyer's review and approval. If the external routing BS and RS in Fig. 17 are long due to lack of IT connection between two change approval systems from two companies, such that,

$$
S_{i j} \ll B S_{i j} \text { and } R_{i j} \ll B R_{i j}, \forall i, j
$$

The Eq. (p.13) can be rewritten as

$$
\mathrm{t}_{\mathrm{engr}} \cong \sum_{\mathrm{i}} \sum_{\mathrm{j}}\left(\mathrm{BS}_{\mathrm{ij}}+\mathrm{BR}_{\mathrm{ij}}\right)
$$

Eq. (p.13.1) is one of the reasons why Eq. (p.2.1) cannot be hold and it is degenerated to Eq. (p.6.1) and (p.6.2) due to inefficient piecewise organization. In this case study, the path in Fig. 17 is changed with a new document "Baseline Document" and a new operation meeting "Weekly Meeting", as our virtual BMS, are introduced to the remote operation.

Eq. (p.13.2) shows the same organizational efficiency as internal operation. The after-QSVee path in Fig 17 is an example of installing a "Business Shield" to an internal organization among value chain while setting up supply chain. With an effective piecewise organization, Eq. (p.2.1) can hold longer and can be pulled back more easily before drifting to Eq. (p.6.1) and (p.6.2) by a much effective organization. 

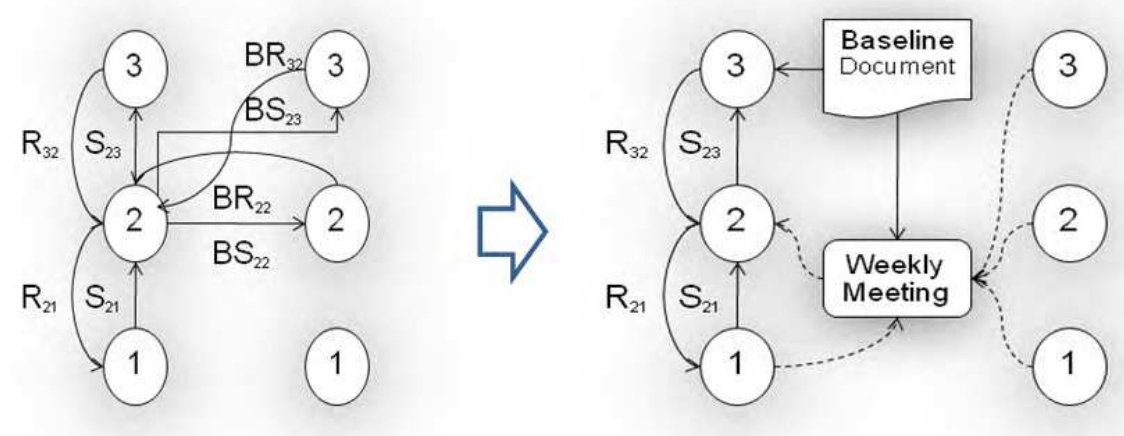

Fig. 17. State diagram of change control path before and after the Quality System Vee Model The "Baseline Document" and "Weekly Meeting" in Fig. 6 enforce $\mathrm{BS}_{\mathrm{ij}}=0$ and $\mathrm{BR}_{\mathrm{ij}}=0$. Eq. (p.13) therefore can be rewritten as

$$
\mathrm{t}_{\text {engr }}=\sum_{\mathrm{i}} \sum_{\mathrm{j}}\left(\mathrm{S}_{\mathrm{ij}}+\mathrm{R}_{\mathrm{ij}}\right)
$$

In our case study, after the three steps: Vee Model setup, virtualization and elimination, people in piecewise organization hardly aware any behaviour is required to change to deal with supply chain network. The piecewise origination operates seamlessly as if a single organization within the same enterprise.

\subsubsection{Rebuild the ownership}

There are four major steps to repair the broken links of a piecewise organization. First, the convergence Cycle is to governing the ownership transferring process. Second, QSVee is the architecture or framework to perform that task. Third, there are also outline special setup and activities from technology transfer to change control in order to assure QSVee Model is a preventive system on quality events. After all those infrastructure are set. The last step is to redefine Responsibility, Authority, and Accountability (RAA) across the piecewise organization in the supply network. RAA is a critical System Engineering approach, especially in Supply Chain Operation. The accountability is normally overlapped with responsibility within a company but that assumption is not holding up while across the company boundary. Since every enterprise with his unique culture and acronym, carrying assumption within enterprise crossing the enterprise boundary is a very common mistake. QSVee model is also part of the system simplification process to create Segregated Network Organization.

The QSVee Model is a default setting in our Operation-Over-The-Net framework in later section. The Operation will cover the rest of the RAA during the Operation Deployment stage for new Supply Chain Network setup. 


\subsection{Planning-centric, proactive quantitative planning}

The BDVee model section mentioned SCSE is Planning-Centric instead of either Procurement-Centric or Customer Relationship dominated. After the QSVee Model implemented, the ownership transferred and quality cost is expected to be segregated under the organization seal and Planning is on the driving seat of the supply chain as fig 18.

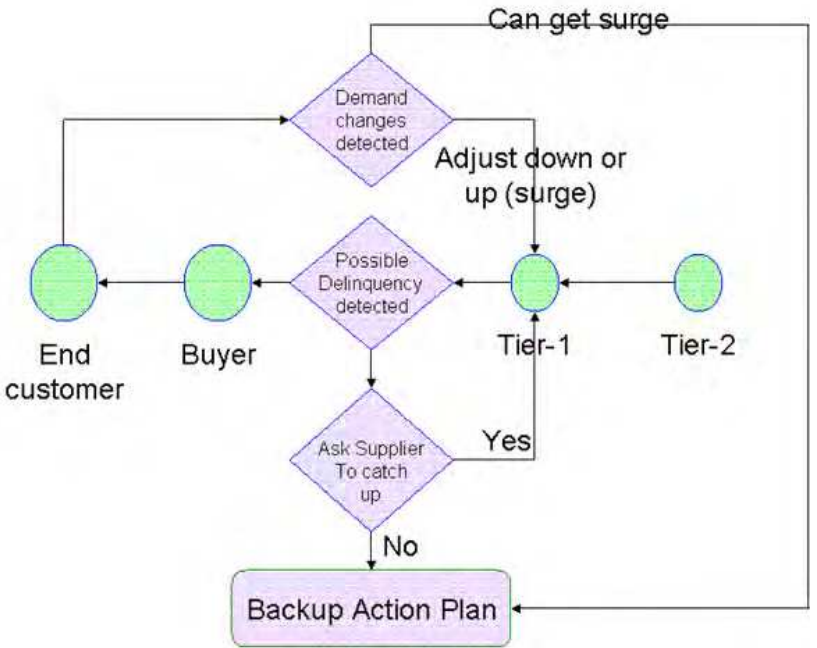

Fig. 18. Allocation flow of detecting a possible delinquency or possible change from customer

Combing business planning and production planning and special design in QSVee as shown in fig 14 and 16 are the two major structure changes to promote planning to be largely extended to be more operation capable in next section. Planning is not only doing the planning job but also working as the first line defender of the supply chain operation such as sampling for quality (Tsai and Yun, 2008). In SCSE, planning is the only organization who is working in daily basis and it is the only resource to perform that daily routine job when most of the engineering are on and off under an on-demand basis. Because of the fast $i+2$ visibility and fast switching capability, planning here is more powerful to perform the allocation process as show in fig 18 to challenge the high volatile market.

Volatile demand from static supply: Long supply visibility not only enables the supplier switching possibility but also opens a new door of supply network design. Given the Variances from supply and demand,

$$
\begin{gathered}
\operatorname{Var}\left(D_{t}\right) \geq \sqrt{S_{1}{ }^{2}+S_{2}^{2}+\cdots S_{j}^{2}} \\
S_{j}^{2}=\operatorname{Var}\left(S_{t}(i, j)\right)^{2}+\text { Surge }_{j} \\
P_{j} / S_{j}=\text { constant }
\end{gathered}
$$

Equations (18) - (20) enable a new approach of supply network design: the volatile, customer-driven demand in consumer market can be satisfied by a static supply array. 
Equation (18) is the boundary of the supply array and Equation (19) is the source of variation where $\operatorname{Var}\left(S_{t}(i, j)\right)^{2}$ is from bad performance and $S_{\text {rarge }}$ is the surge capability that supplier committed to the buyer. Equation (20) is the allocation priority factor which implies higher flexibility means higher price. Volume, flexibility, contract length, performance are all planning factors that will affect cost and supply capability in a dynamic supply network.

Fig 18 demonstrates changes could be from supplier due to delinquency or from customer. Either change will break the demand supply balance. So the supply network should accommodate whatever change at the customer end and keep supplier as static as possible in the "long lead time and cycle time" semiconductor industry. The Equation (11) can be rewritten as

$$
\sum \mathrm{D}(\mathrm{t})_{\mathrm{i}}-\sum \mathrm{S}(\mathrm{t})_{\mathrm{i}}=\sum \mathrm{B}(\mathrm{t})_{\mathrm{i}}, \sum \mathrm{B}(\mathrm{t})_{\mathrm{i}}<\mathrm{S}_{\mathrm{j}}^{2}, \mathrm{t} \leq 0
$$

In the Participatory Production, the planning taking more responsibility to check CoC with the LLL service provider in the production stage of fig 11. It has partial function on manufacturing, quality control and production control functions in a regular enterprise as well. In some extreme setup with a right candidate, Leader in Planning is uplift as Virtual Manufacturing Manager to manage most of the post-milestone $\mathrm{C}$ activities in the acquisition cycle.

\section{Operation-Over-The-Net (OOTN)}

After building up the branch of the supply network via the BDVee Model, transferring ownership to supplier and rebuild the piecewise organization via the QSVee Model, an Operation management to sustain the supply chain is next challenge to perform in a postmilestone $C$ production. Since the architecture, organization, activities are all set up to this stage, this section is to elaborate the principle to setup OOTN and how those elements in pervious sections putting together and run it. The OONT must overcome the four natural barriers: (1) enterprise is built to be differentiable, (2) business relationship is dynamic, (3) trade secrecy is need-to-know, and (4) each enterprise has unique culture. In term of SCSE uniqueness, the OOTN also demonstrates how the Planning-Centric architecture is scalable to deal with all kind of supply chain network from simply backward compatible to SCOR, to be the virtual manufacturing manager role in large, complicated application. In "connectivity", OOTN will show its capability to deal with heterogeneity of supply chain network.

\subsection{OOTN is a back-to-basic approach}

This solution assumes the multiple-enterprises operation environment today is like the Operation Management (OM) among internal organizations 20 years ago: immature in IT automation, but full of possibility (Tsai et al, 2009). The back-to-basic principle results a top-down approach: copying functional requirements from internal OM organization to OOTN organization is the less resistant path on behavior change in order to treat OOTN as an extended $\mathrm{OM}$ to managing external resources. For example, a planning function in internal OM needs a peer in OOTN to response timely and accurately. Fig 19 below is the 4-steps OOTN implementation process that compiling the 3D model in a closed-loop manner. 


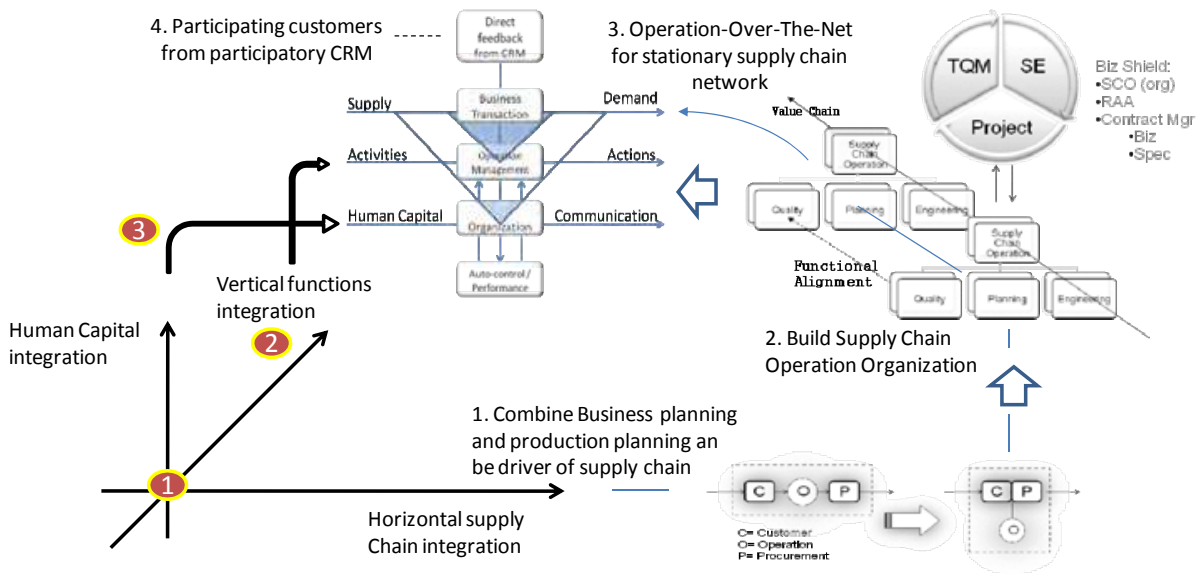

Fig. 19. A closed-loop, 4-steps OOTN implementation process

1. To reform the organization to be network-ready by implementing the ESE elements and combining the business planning and procurement.

2. To form the virtual organization chart for operating the internet based OM System. The Supply Chain Operation (SCO) is the core of OM which acts as an integrator of SCM to optimize the existing resources, enforce the existing operation disciplines or adapt new disciplines, and etc. Its ultimate goal is to assure smooth operations throughout the supply chain. That is equivalent to an Operation Manager or Fab Manager role in internal OM. Three basic disciplines are required to perform the job smoothly are Total Quality Management (TQM), System Engineering (SE) , and Project Management (PM) in additional to the domain professional.

3. There are three basic functions connecting to the SCO integrator: Planning, Quality, and Engineering. Both the Quality and Planning functions detail have been covered by the pervious section "Quality Vee Model for Piecewise Organization" and "Planning-Centric, Proactive Quantitative Planning". For engineering, this chapter is intend to leave it opened since it is totally enterprise and even product dependent even within a enterprise. As mentioned in the section "Virtual Enterprise Composition Process", this chapter is to provide a quick adaptation with "container" in the $3 \mathrm{C}$ adaptation process. The engineering potion part of the "Operation Deployment" step during the setup stage and supported within the Quality System procedure when it settle in "Operation and Control' during the QSVee realization process for transferring the ownership. That "Operation and Control" is the charter of SCO organization for the OOTN. The Virtual Organization is a peer-to-peer structure that requires coordination from supplier or customer to perform perfect functional alignment. The aligned virtual organization is an organic complex which fully meets the integration requirements, both internally and externally, to overcome the four barriers of implementing Supply Chain Collaboration (SCC).

4. Inside the OOTN Architecture, there are 3 horizontal workflows and 1 vertical workflow. Beside the 3 horizontal flows that operating with the SCO along the supply chain. However, that is too long for a supply chain to react with the end customer. The vertical flow is a very unique design to connect the OOTN to the end customer or the collaborative, common pool that connectable to end customers. That turn the topology 
of the chain structure into a start topology where the customer in the center in other

dimension. That is a very important design for customer-centric supply network.

Different problem statement leads to different solution. The back-to-basic OM approach is heading different direction of the "Do best, IT does the rest" mentality that trap the executive in the decision mind map and cannot escape from the maze. OOTN is a very simple architecture where IT tools are evaluated based on their cost, time-to-market, and being human-centric to meet the dynamic life cycle of a branch in supply chain network. OOTN and SCO organizational development is compiling the basic continuous improvement approach that aligning with the three-stage organization theory that can be used to improve operations throughout the supply chain: (1) efficiency, (2) effectiveness, and (3) began to incorporate the ideas and expertise of their suppliers and partners into the management of the supply chain, from within industry to crossing industry boundary (Melisa and Snow, 2007).

\subsection{The OOTN architecture in business level}

The OOTN architecture is a top-down design using system engineering approach. It views system as a whole and conducts SCC via the periodic OM over the stationary supply chain. The traditional on-site management is easy to start but very costly to operate, which is often ineffective, and lack of right ownership after all. That on-site concept is replaced by the online collaboration OOTN in our best practice. In fact, OOTN is the answer to the executive to help him getting out of the mind map maze since it is an extended organization from the internal OM organization that the executive know how to approach without putting an IT up front such that he can talk the language he understand, and the people he knows. The scope of OOTN in business level is defined in Table 3 which states a process to support operation level management.

\begin{tabular}{|l|l|l|}
\hline \multirow{2}{*}{$\begin{array}{l}\text { Functional } \\
\text { level }\end{array}$} & \multicolumn{2}{|l|}{ Application Level in Management } \\
\cline { 2 - 3 } & $\begin{array}{l}\text { Operation over Supply Chain } \\
\text { Network }\end{array}$ & $\begin{array}{l}\text { Business over Value Chain } \\
\text { Network }\end{array}$ \\
\hline Decision & Compliance & Strategy \\
\hline Process & OOTN & Allocation \\
\hline Activity & Responsive & Re-structure \\
\hline
\end{tabular}

Table 3. OOTN Integration within Enterprise

Table 3 defines scope therefore identifies the system requirements as what is needed to operate it and result in the SCO. This requires interdisciplinary efforts from Planning, Quality, and Engineering as a team at functional level to response to activities across the Supply Chain Network to assure the compliance from business level deployment. Table 3 also indicates that any possible failure to compliance will alert to higher level which might trigger business level allocation process and back to planning execution in fig 18 from business decision over the value chain network. That is another reason why SCSE architecture is putting Proactive Planning in such a fusion role between business, production, and front line defender or engineering for fast switching capability in volatile market. From the definition in Table 3, OOTN is also an infrastructure connecting e-Service 
on frontend and MES on the backend. In step 3, the OOTN is operating over the System Architecture of OOTN which has direct interface to end customer to have them directly interactive with the OOTN on the back office to enhance responsiveness of the entire supply chain, hence customer experience to the service provided.

\subsection{System architecture of OOTN}

In terms of architecture, OOTN is derived from ISO 7 layers protocol, as a multidimensional gateway that transmits events therefore actions along the supply chain horizon. OMS, in this analogy, is equivalent to the network layer in level 3 where the OOTN receive event alert from one spot, move upward to higher level to process, make decision, move back to OM, and route activities to the right spot in SCN. The simplified form of system architecture of OOTN is presented in step 3 of Fig 19. The OM is in the centre of vertical and horizontal workflows. In the OOTN architecture, only the Supply-Demand workflow in horizontal direction is covered by current Supply Chain Operation Reference (SCOR) model that makes the OOTN model backward compatible to SCOR standard from supply chain council. The other two workflows "Activities" to take actions and "Human Capital" to communicate are additional to SCOR. The workflow in vertical direction is a very unique design that allows CRM of the entire supply chain on the front end to feedback directly to the Operation Management over-the-net to make the supply chain more responsive. Here are the other key features of each block:

- Activities-Actions path: in additional to the transactional path, engineering activities in complicated supply chain is not covered by SCOR, the core of OOTN to route activities.

- Human capital-communication path: another element in addition to the transactional path in order to communicate and collaborate activities or transaction over-the-net crossing enterprise boundary, which is different from working internally and requiring different kind of human capital. It is equivalent to Data Link or Physical layers of ISO model.

- Direct Feedback from front end or CRM: OOTN architecture is a customer-centric structure built for networked enterprise and with direct feedback algorithm and workflow setup that create a new, fastest path of reacting to end customer.

- Auto-control / Performance unit: monitoring unit to assure all components of the system are well-connected and well-measured to provide fast feedback to OM in a positive loop.

The 4-steps OOTN implementation in fig 19 is a closed-loop process to response to the original requirements of the "Simple 3D Model of SCM mechanics for Nested Society" and the proposing solution of the Enterprise Development path in "Bidirectional paths to Enterprise Development and Personal Development within the 3D Model". The closed loop in macro view starts from the horizontal supply chain integration, then perform the veridical functions integration via the SCSE implementation to setup the value chain, and finally complete the Human Capital integration. There are also micro views for each individual dimension in the system architecture of OOTN: horizontal supply chain vs. the Supply-Demand pair; Vertical functions integration vs. the Activities-Actions pair; and Human Capital Integration vs. the Human Capital-Communication pair. All the 3 loops are fused together in the OOTN architecture in fusion chamber aspect including the direct feedback loop e-CRM with the end customer. That unique design allows SCSE 
to connect private space in enterprise along the chain and directly to end customer in public space.

VI.4 Operating the OOTN Backbone: OOTN is a backbone of SCN in network and telecommunication sense because it routes activities via the IT network. Therefore it is also backbone of organization and operation in management sense. It is designed to be backward compatible to SCOR model in business transaction. Furthermore, it is backbone of Peer-toPeer computing in terms of protocol, architecture and business algorithm that support stationary enterprise. With all those compatibility, managing SCC by employing OOTN can take a lot of advantages:

- Only few specific IT setup is required to add a supplier or customer to an existing SCN or form a new SCN

- High degree of freedom to plug in differentiable workflow, adapt different cultures, and seal trade secrecy through human interface to OOTN

- $\quad$ Fast ramping up and switching supplier to coup with dynamic business relationship

- Not constrained by IT connectivity, internal pre-programmed complex procedure, or those external consultant told to do, therefore be able to deal with business dynamics. The success of SCC result in good quality, efficiency, and effectiveness is mostly credited to the fact that stake holders can focus on business process, procedure, engineering innovation, and commitment of continuous improvement in periodic OM.

- Good scalability: If business relationship is long-term or the business scale is justifiable to build multiple enterprises workflow or application. Invest the workflow permanently with no regard.

- Fully customized in each branch of the heterogeneity of supply chain network since OOTN is KNOWLEDGE CONTAINER design.

The highly scalable, flexible OOTN which disjoints IT and SCC make big differences comparing with current IT approach. The OOTN architecture is compiling differential competition principle (Porter, 1998) and Service Oriented Architecture or E2OPEN are not. Business owner can therefore perform business architecture design freely to optimize value network and position such as resources allocation, asset ratio decision etc then do IT consideration later. Those flexibilities are critical to capital intensive, complicated industries such as aerospace, semiconductor. In our study, scalability provides stable structure, and that enable knowledge management. Stationary provides another dimension of scalability by making business architecture geographically independent. Those are key elements of virtual enterprise to keep their differentiable workflow as the core competency under the nested society. The OOTN or equivalent capacity is a must-have ability today as the right hand of the CEO to manage external resources.

\subsection{Operating the OOTN backbone}

OOTN is a backbone of SCN in network and telecommunication sense because it routes activities via the IT network. Therefore it is also backbone of organization and operation in management sense. It is designed to be backward compatible to SCOR model in business transaction. Furthermore, it is backbone of Peer-to-Peer computing in terms of protocol, architecture and business algorithm that support stationary enterprise. With all those compatibility, managing SCC by employing OOTN can take a lot of advantages:

- Only few specific IT setup is required to add a supplier or customer to an existing SCN or form a new SCN 
- High degree of freedom to plug in differentiable workflow, adapt different cultures, and seal trade secrecy through human interface to OOTN

- $\quad$ Fast ramping up and switching supplier to coup with dynamic business relationship

- Not constrained by IT connectivity, internal pre-programmed complex procedure, or those external consultant told to do, therefore be able to deal with business dynamics. The success of SCC result in good quality, efficiency, and effectiveness is mostly credited to the fact that stake holders can focus on business process, procedure, engineering innovation, and commitment of continuous improvement in periodic OM.

- Good scalability: If business relationship is long-term or the business scale is justifiable to build multiple enterprises workflow or application. Invest the workflow permanently with no regard.

- Fully customized in each branch of the heterogeneity of supply chain network since OOTN is KNOWLEDGE CONTAINER design.

The highly scalable, flexible OOTN which disjoints IT and SCC make big differences comparing with current IT approach. The OOTN architecture is compiling differential competition principle (Porter, 1998) and Service Oriented Architecture or E2OPEN are not. Business owner can therefore perform business architecture design freely to optimize value network and position such as resources allocation, asset ratio decision etc then do IT consideration later. Those flexibilities are critical to capital intensive, complicated industries such as aerospace, semiconductor. In our study, scalability provides stable structure, and that enable knowledge management. Stationary provides another dimension of scalability by making business architecture geographically independent. Those are key elements of virtual enterprise to keep their differentiable workflow as the core competency under the nested society. The OOTN or equivalent capacity is a must-have ability today as the right hand of the CEO to manage external resources.

\subsection{Assure supply continuity}

Having multi-tier supply visibility and being able to quickly respond are not enough to assure supply continuity. The total supply and demand must satisfy Equation (21) below in order to maintain supply continuity, which is a business requirement, not a solution. Any interruption caused by quality problem or up-sized demand from end customer can break the condition in Equation (21).

$$
\sum_{\mathrm{j}_{\mathrm{i}}=1}^{\mathrm{j}_{\mathrm{i}}} \sum_{\mathrm{l}_{\mathrm{j}_{\mathrm{i}}}=1}^{\mathrm{n}_{\mathrm{j}_{\mathrm{i}}}+\mathrm{m}_{\mathrm{j}_{\mathrm{i}} \mathrm{t}}} \mathrm{S}_{\mathrm{t}}\left(\mathrm{i}, \mathrm{j}_{\mathrm{i}}, \mathrm{l}_{\mathrm{j}_{\mathrm{i}}}\right) \geq \mathrm{D}_{\mathrm{t}}(\mathrm{i})
$$

The fast supplier switching capability in OOTN provides a new flexibility to deal with the volatile demand or unstable supply, thus is capable of assuring supply continuity in all economical cycle. We have adapted the concept of Process Capability Index CPU as the method of handling demand or supply volatility, which is estimated as

$$
\mathrm{CPU}=\frac{\mathrm{USL}-\bar{\mu}}{3 \sigma}
$$

If only considering the variation of supply and demand, i.e. $\mu=0$, then USL $\approx 3 \sigma d$. Therefore, if ignoring $\mu$, which means all suppliers commit total quantity but may not satisfy individual shipment, the supply continuity can be satisfied if and only if, either Equation (23) or Equation (24) can be satisfied as shown in Fig 20. 

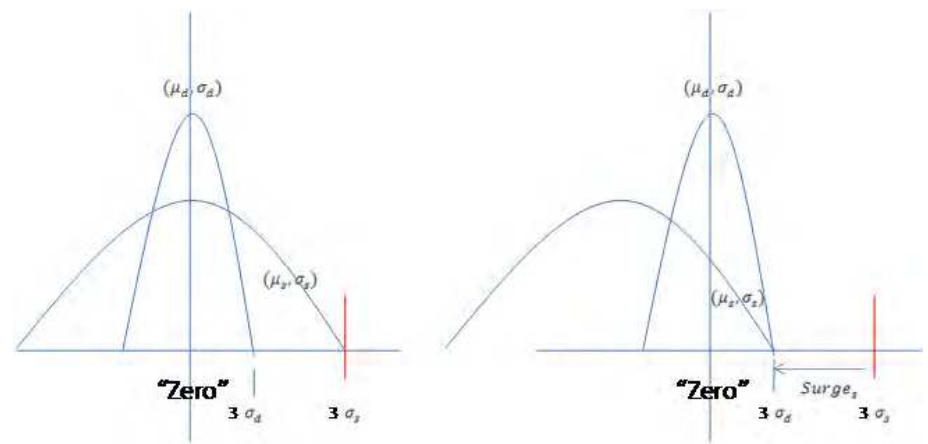

Fig. 20. Surge capability

$$
\begin{gathered}
\sigma_{\mathrm{s}} \leq \sigma_{\mathrm{d}, \text { or }} \\
3 \sigma_{\mathrm{s}}-\text { Surge }_{\mathrm{s}} \leq 3 \sigma_{\mathrm{d}}
\end{gathered}
$$

Both Equations (23) and (24) are derived based on the assumption of normal distribution to simplify the demonstration. The surge capacity Surge $_{s}$ is the extra reserved supply capacity collected from all suppliers as shown in Fig 21.

Equations (22) - (24) enable a new approach of supply network design: the volatile and customer-driven demand in consumer market can be satisfied by a static supply array. Equation (23) is most likely not feasible therefore Equation (25) is a more practical solution in designing supply network. In some industries, if the qualification time or setup time for a new supplier takes too long, fewer suppliers will be added into the supply network. In this case, using the surge capacity Surge ${ }_{s}$ is the only way to deal with the demand or supply volatility. However, this may not be feasible as well in a hot season and it can be quite costly. Usually price for surge capacity is proportional to its volume. Higher surge capacity implies higher flexibility which also means higher price. Volume, flexibility, contract length, performance are all planning factors that will affect cost and supply capability in a dynamic supply network.

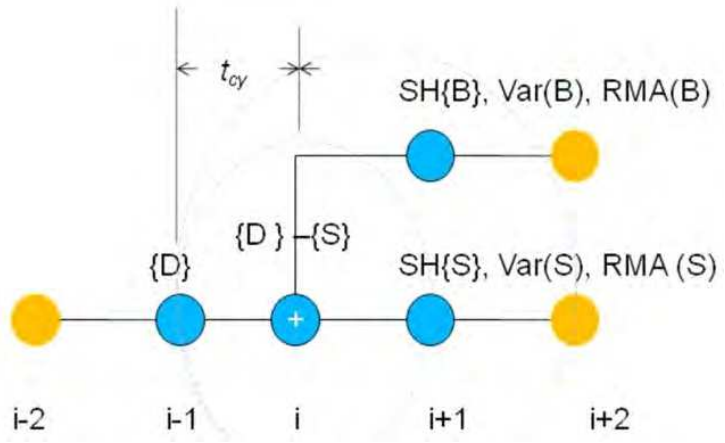

Fig. 21. Multi-tier supply collaboration

Having planning on the driver seat will ensure fast responsiveness therefore minimize cost and assure supply continuity. However solving and preventing quality problem, and 
qualifying quality suppliers and surge capability are still engineer or SCO integrator's job. Optimization is not considered in OOTN as it is either applied to internal resource optimization or value network optimization at the business levels defined in Table 3.

\subsection{Minimize bullwhip effect}

OOTN is designed to enforce supply continuity collaboratively therefore minimizes bullwhip effect as well. The demand variation from customer $\operatorname{Var}(\mathrm{D})$ is not controllable but order variance $\operatorname{Var}(\mathrm{Q})$ can be manageable. Equation (25) quantifies bullwhip effect and Equation (26) shows how the variance is amplified along a decentralized supply chain.

$$
\begin{gathered}
\frac{\operatorname{Var}(\mathrm{Q})}{\operatorname{Var}(\mathrm{D})} \geq 1+\frac{2 \mathrm{~L}}{\mathrm{p}}+\frac{2 \mathrm{~L}^{2}}{\mathrm{p}^{2}} \\
\frac{\operatorname{Var}\left(\mathrm{Q}^{\mathrm{k}}\right)}{\operatorname{Var}(\mathrm{D})} \geq \prod_{\mathrm{i}=1}^{\mathrm{k}-1}\left[1+\frac{2 \mathrm{~L}_{\mathrm{i}}}{\mathrm{p}}+\frac{2 \mathrm{~L}_{\mathrm{i}}^{2}}{\mathrm{p}^{2}}\right]
\end{gathered}
$$

Our proactive planning unit is a highly collaborated but centralized SC control unit that has the best potential of eliminating or minimizing the Bullwhip effect. If the $t_{\text {avaliability }}>L$ condition can be met, supplier can back fill or refill the order to absorb the variation $\operatorname{Var}\left(\mathrm{D}_{t}\right)$ from buyer, or buyer can reallocate the variation to other suppliers following the disciplines described in Equations (21) - (26). The multi-tier supply visibility and control schema enables a new way to manage collaborative supply chain network and gives a new boundary. In OOTN, Planner who is responsible for Master planning is also responsible for Supply Planning and Production Planning. Thus the lead time or response time can be eliminated. Therefore Equation (25) can be simplified as,

$$
\operatorname{Var}\left(\mathrm{D}_{\mathrm{t}}\right) \equiv \operatorname{Var}(\mathrm{Q})
$$

If Equation (3) is met, which means the supply continuity is achieved, by applying Equation (25.1) repeatedly for all supply chain stages, Equation (26) can be extended to:

$$
\operatorname{Var}\left(\mathrm{D}_{\mathrm{t}}\right) \equiv \operatorname{Var}\left(\mathrm{Q}^{\mathrm{k}}\right)
$$

The bullwhip effect is based on the fact that there are delays from one stage of supply chain to the next. The OOTN structure is to enforce the quick responsiveness to demand variation $\operatorname{Var}\left(D_{t}\right)$ at every stage of supply chain. With the multi-tier supply visibility, planner can proactively make planning decision before supply disruption can take place.

\subsection{Human capital in OOTN:}

The word "Virtual" and the complexity of workflow in Fig 19 have briefly defined the human capital requirements in OOTN architecture. The highly integrated activities to be conducted requires a single man who is capable of executing and driving TQM, SE, PM, and even PLM during the product lifecycle, or, an equivalent organization who can conduct those communication and execution effectiveness and efficiency. That is a capability issue where a simple production line only needs one but a complicated production line have to be multiple tasks. The "virtual" implies that particular integrator must be capable of working with Planning, Quality, and Engineering as well in terms of organizational structure on both supply and demand ends, to be the Operation Manger over-the-net covering functions required in Fig 19. OOTN is architecture to "Connect" buyer and supplier that means to utilize all existing resources on both sides is design principle. Therefore, SCO is virtual and 
do does OOTN. The primary human resource to run the OOTN has to be very experienced to have full picture of how organization is working internally and externally otherwise it will be very easy to get lost in the piecewise organization. There are lots of dark sides:

- Those kinds of human capital are very difficult to find

- Executives does not know exactly what human capital he wants when he is still trapped in the executive mind map

- No such job grade in most human resources category. A human resource finding a candidate for procurement will not fit that needs.

- No exiting payment schema to justify those jobs managing high percentage of revenues or cost outside of enterprise but with no employee inside reporting to him. There will be more challenges when the world is confirmed to heading phase 3 by Economic Policy Institute (EPI): the statistic said $1.4 \mathrm{M}$ jobs were created overseas by U.S. companies, compared to $1 \mathrm{M}$ domestically in year 2010 (Raynor, 2010).

There are two ways to solve those challenges in human resource. The executives and human resources need to adjust and school needs to "produce" right human capital to reduce barrier. SCSE discipline is designed for that purpose with framework includes all those material and condiments from system engineering to IT. To be familiar with SCSE will help a right human capital to perform the job right with less efforts and risk.

\subsection{Best practice applying OOTN}

There are two major dimensions in improvement by adapting the OOTN architecture: the supply continuity and customer-centric organization even it is piecewise, and "temporary" in term of the full acquisition cycle. The former is for delivery and the later is for sustainment independent of the length of the acquisition cycle. The direct linkage to end customer allow the players of the chain decouple from the acquisition cycle regardless to while milestone or how long a supplier stay in the value chain. The table 4 below is one of the best practices that the research team sees how well the OOTN can last with no major interruption and continue to roll even in the sustainment cycle. That is the longer data the team can see for a product in consumer market when the design team wants to challenge how good the Supply Network Reliability in SCSE design. It has been way past 3 years requirements and 10 years for automotive. For the 15-25 years for military industry, does not have one product to prove that yet. The table 4 below is the result from the experimental facilities that executing this model for more than 10 years with zero disruption since it started. It has been delivered more than a Billon chips to end customer from the supply network and become sole supplier of the customer due to his superior deliverability on performance from Quality, Service, Delivery, and Price over the time. The suppliers are switching on and off dynamically and network level allocation are working normally as expected to archive the $400 \%$ volatility in historical record.

The back-to-basic approach in the best practice reveals one very important signal. The tripleA enterprise requirement is a rapidly adaptable infrastructure in all level with fast switching capability to suppliers.The back-to-basic approach is saying the engagement, disengagement processes of one supplier is to leverage the experience of IT evolution of the past 20 years but not the continuity of anyhow. Every branch is different therefore the supply chain heterogeneity is norm. Therefore back-to-basic approach is an effective strategy that quickly repeats the learning from 20 years IT evolutions in the past, "make it works" first then "make it productive". This research result explains why the poor B2B system integration 
result in Table 1 and where the executives mind map coming from. Accenture invented the "Fourth Party Logistics (4PL)" in 1996 but they abundant it for same reason. That is a right concept but the physics they embrace is wrong, and, it failed. SCSE try to define the physics right for the virtual enterprise but it needs IT facilities, right IT consultant players to accelerate the IT evolution to a right direction.

\begin{tabular}{|c|c|c|c|c|c|c|c|c|}
\hline Year since started & Yr-1 & Yr-2 & Yr-3 & $\overline{Y r-4}$ & Yr-5 & Yr-6 & Yr-7 & Yr-8 \\
\hline Device.Supplier & 4 & 8 & 10 & 10 & 8 & 14 & 14 & 17 \\
\hline Family-A Yield Inc. & & $10 \%$ & $0 \%$ & $2 \%$ & $1 \%$ & $3 \%$ & $0 \%$ & $0 \%$ \\
\hline Family-A $>3 \%$ event & 0 & & 2 & 0 & 1 & 0 & 0 & \\
\hline Disruption(Family-A) & 0 & 0 & 0 & 0 & 0 & 0 & 0 & 0 \\
\hline Family-B Yield Inc. & & & $165 \%$ & $6 \%$ & $1 \%$ & $4 \%$ & $0 \%$ & $-1 \%$ \\
\hline Family-B >3\% event & & & 0 & 0 & 0 & 1 & 0 & 2 \\
\hline Disruption(Family-B) & & & 0 & 0 & 0 & 0 & 0 & 0 \\
\hline Total $>3 \%$ event & 0 & 1 & 2 & 0 & 1 & 1 & 0 & \\
\hline Total Disruption & 0 & 0 & 0 & 0 & 0 & 0 & & \\
\hline
\end{tabular}

Table 4. 10 years Zero Interruption since Started

\section{Participatory production}

The beauty of physics is capable to theorize the possible outcome of future evolution of nested society if this is right hypothesis. The solar system took tens or hundreds of millions of years to have the most of the debris either removed by the planets or moved into stable orbits resonant with those in the planets. Same as the nested society, the IT evolution will take time whether it is the public space, private space in personal development, or private space in virtual enterprise. The research team visioning the hypothesis therefore it has the result as SCSE from the efforts in last decade. This section is continued to extend that hypothesis after the 10 years success to the next decade. The SCSE is now in high maturity level on the virtual enterprise part that is covering well in the 1st dimension and 2nd dimension of the 3D model. It means the Enterprise Private Space (EPS) is matured both in physics and real practice in industries but the 3rd dimension to be connectable to the Private Personal Private Space (PPS) still weak and lack of sufficient volume data to fully validate the detail of the equation although the experimental facilities are working grate as expected.

The continue trend of the SCSE in virtual enterprise that foreseeable to the "Paired, Bidirectional decision-making flow" is Participatory Production. It has two levels as well in term of complexity. The level on is only cover the 1st and 2nd dimensions which is already validated in a very complicated supply chain that applying the process in this chapter. This section is to visioning the coming decade is the decade to fully validating the "Paired, Bidirectional decision-making flow" in both ways. The Social Network just starts to mature. It will take time for the large chunks of rock to condense into planets.

\section{1 "Creativity" =" Innovation" if "R\&D = [R@a] U [ D@b]"}

The current Participatory Production evolution is just about to give high DoF for Integrated Device Manufacturing (IDM), which integrates resource vertically for effective innovation in the horizontal dimension. In this chapter, the SCSE is very solid in post-milestone C production; however, it is still lack of volume data in early milestone in low technology 
maturity stages. Fortunately, the physics tells us the "Virtual Enterprise Composition Process" is generic and applicable to full acquisition cycle. Hypothetically, the Research and Development in early stage could be a collaborative effort which is what the DoD already does for many years. Those are not common in commercial environments but the research team already sees more and more cases are observed although the result are not traceable or available yet to public. This section is assuming the equation of "R\&D = [R@a] $U$ [ D@b]" and the availability of the "Paired, Bidirectional decision-making flow" are both valid. Those assumptions will come to next level of Participatory Production in ecosystem as illustrated in fig 22. In the chart, there are couples of new elements that is not common in today practices,

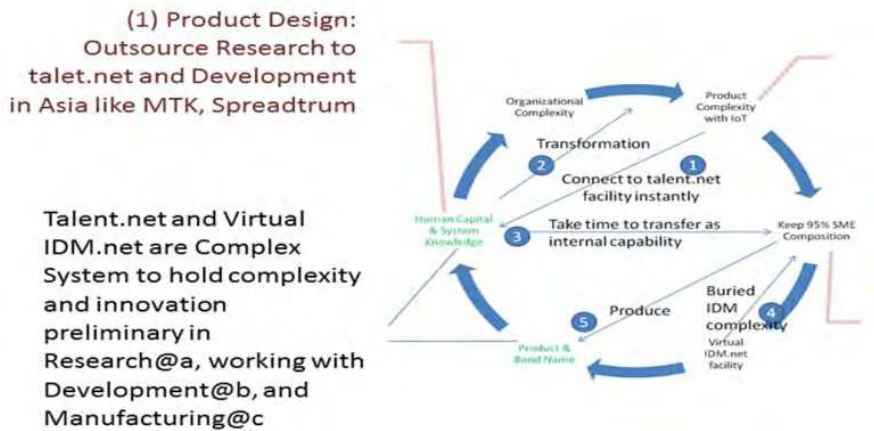

(2) Keep Creativity: Outsource both R \&D to ffr.net, focus on customer care about and product features

(3) Keep Biz focus: Outsource Mfg process to virtual IDM.net by keeping industrial design and/or focus technology enablers

Fig. 22. Decentralization Invocation Cycle of Multi-tier supply chain collaboration

A virtual IDM facility: A public facilities can execute "R\&D = [R@a] $\cup$ [ D@b]" to lower the barrier of innovation cycle

- A Human Capital Pool with System Knowledge: A public facilities that provide PPS which is connectable to EPS to compile the 3rd dimension of the 3D model. The talent is grouped by system level knowledge such that the freelancer or SME is powerful enough to deliver full product therefore capable to earn their living by staying in the facility.

- $\quad$ Product complexity with Internet of Thing (IoT): the sensor network will give more life to the participatory production when sensor is on as an extension of human beings that can reach, see, or feel remotely.

- full Enterprise Life cycle Management available that allow the bottom up path of the "Paired, Bidirectional decision-making flow" actively form ecosystem

Those are new elements that are being theorized to be happened and validated in small volume facilities. Due to the huge complexity of adding those assumptions onto the nested society it has been causing huge challenges on system complexity itself, and computing power to conduct the responsive result back to the other end of the cloud. The research team has been identified at least 3 hardware components to be the hardware accelerator for the nested society infrastructure. The cloud computing, the physics of the nested society and the hardware are going to reform and redistribute the function being performed today in daily activities. Nothing change of the input, output of the production acquisition cycle but just the way of collaboration, and hardware, software to implement it will be very different. 


\subsection{Maturity and available facilities}

The concept of Participatory Production is not new and it is originally from the purpose of the term "industrial accumulation", which is accumulation of thousands of small factories in a region of Suwa-Okaya area of Japan to perform Participatory Production (Kita, 2008). This chapter rename the Suwa-Okaya to "Participating Production" is to capture the nature of IT in connectivity and the bottom-up power of the IT revolution that the original name does not coves. During the revolution process, the power is continuously shifting to individual and barrier of the innovation that the IDM holding will be dramatically reduced.

The concept of about "Creativity" can be equal to "Innovation" is also not new when Mr. Pink, author of "A Whole New Mind: why right-brainers will rule the future" promotes the new paradigm of "Conceptual Age" where jobs are "high concept or high touch" can't be exported. In the increasing global competition in next decade, the research team foresees both ends of the economic forces are converging to the same trend but in the opposition direction. Fig 22 can demonstrates that trend in this way:

- Innovation leader, US represents: The" APPLE STORE" is a leader to demonstrate the power of networked organization and the success of iPhone, IPod, and IPad turns hardware into almost no value in competitive advantage sense. See the elements Apply holds in the fig 22: "Product and Brand Name", "System Knowledge", and key components in IDM such as A4 Processor and touch screen IP. In a iPad sells at \$499, the EMS Foxconn only charges $\$ 11.2$ to Apply, or only $2.2 \%$ of the total sale. COE of Acer, Nokia are stepped down. Blackberry, Lenovo are all under challenges. Apply is representing the "Concept Age" in enterprise but once the fig 22 like infrastructure is up to certain stage, SME or freelancer can do it too.

- Manufacturing leader, China represents: That is very interesting finding in our research team: China is going in the opposite direction standing where they are strong. Not mention that China has end 110 year US leadership and become world's top manufacturing nation with $19.8 \%$ of the world's manufacturing output vs. $19.4 \%$ in US (Merco Press, 2011). SME with less than 300 employees are $91.9 \%$ in China (Li and Cheng, 2003) Therefore the largest, fully plannarized channel in e-commerce such as overcrowded B2B2C market is in China (Kai, 2010). China is holding the creativity in a very large pool such as the $80 \%$ giant Alibaba (Matthews, 20008), and the clone phone in Shenzhen area. They do not have the system knowledge yet, but the government intends to skip the current generation to jump on the next generation such as clear energy and IoT.

Even though the overall maturity of the "Creativity" = "Innovation" is low but the commercial availability of the infrastructure already in place such as the "talent.net" and "Virtual IDM.net" in our experimental faculties and partners facilities. If the physics is right, the world is converging the way the physics calculates and somebody is picking up the position and become third-party service provider of the industry

\section{System scalability and model spectrum}

When WalMart is defined it is an IT company, it creates WalMart and sooner he becomes leader in retailer market with his innovative VMS model and efficient SCM. Similar in Amazon.com, when it is also defined Amazon.com an IT company around the end customer sale experience, it becomes the leader on online e-commence with innovative SCM on warehouse, logistics, and cloud computing facilities. Both of them are taking full advantage 
from IT and become industrial leader on his territory. This section is having the brief description of what kind of IT infrastructure can be the backbone of the SCSE architecture, EPS, and PPS to support the physics of running the nested society.

\subsection{Business Gateway Model (BGM)}

The rule of "Do Best, Outsource the Rest" has been modified to a new rule: "Cover what you do best, Link to the rest" for superior Agility (Jarvis, 2007). The IT infrastructures to support the virtual enterprise setup mentioned in the " $3 \mathrm{C}$ Quick Adaptation process "of the PPS is presented in fig 23 below. The advantage of being a virtual enterprise to be on-demand in resources, conceptually, however, the word "ON-DEMAND" has two meaning-- agility and feasibility. Beside the OOTN in operation level in feasibility, the fig 23 below demonstrates the Business Gateway architecture on business level feasibility to deliver AGILITY of Supply Chain Network. The architecture on the right has similar structure to the ISO 7-layers protocol: a public platform in Lower Logistics layer (LLL) and a business domain specific Upper Private Layer (UPL). To put cash flow inside LLL, as one of the services of LLL provider, is an optimal business solution by proven model in Value-Added Logistic (VAL) player for 13 years in this case study. This design is extremely important for the long value chain for Participatory Production with high product value which means high outstanding inventory cost in the supply chain, or, freelancer type of virtual enterprise with super high leverage ratio in finance. The top layer in LLL is Business Layer which is the gateway layer and route operational activities upward to UPL via the OOTN layer above, which acts as a session layer. The gateway layer also route physical goods moving downward in LLL to next step of the chain with financial care option. That design serve the purpose to connection-oriented enterprise to provide the capitalist competitive 'freedom" to any enterprise to cascade resources into piecewise organization in an on-demand basis.

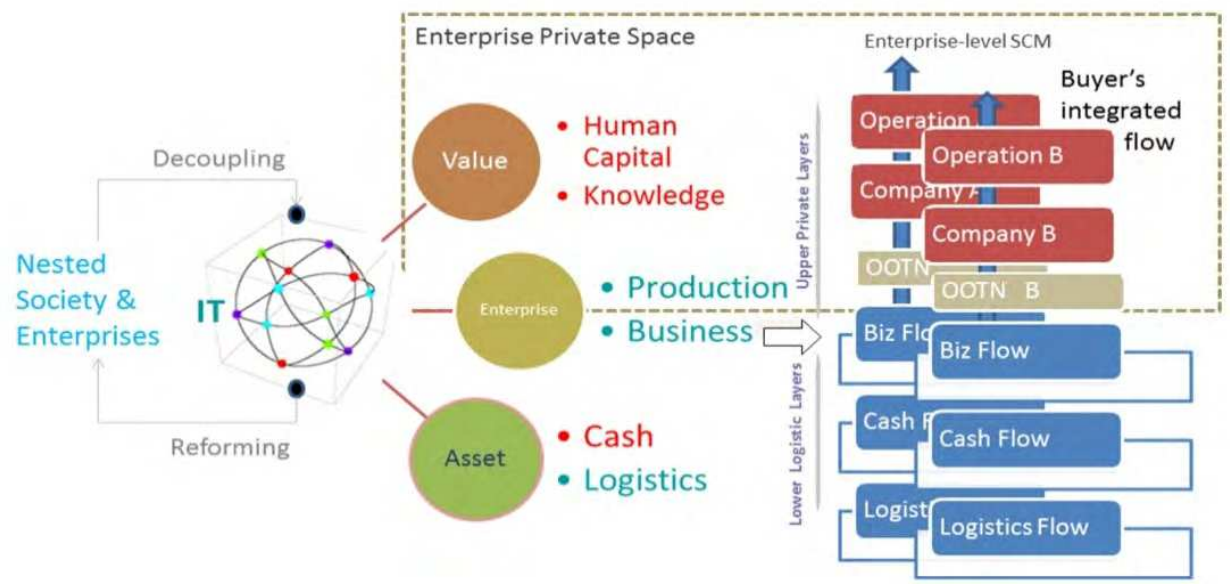

Fig. 23. The 1+6 flow model and its mapping to the ISO 7-layer like Model for Business Gateway

The BGM architecture is sponsored by the 3-tiers $1+6$ flow model as showing on the left side of chart. The 3D model is constructing for the needs in the supply chain physics but it is 
breaking down into a 1+6 flows architecture when it comes to IT implementation. The 6 flows are "Logistics", "Cash", "Business", "Production", "Knowledge", and "Human capital" in the 2nd tier. The IT flow is the root on top. The 6+1 IT architecture is the core of the SCSE model and architecture in our research for the nested society in post-Internet era. The BGM is also modulated and the top UPL is exchangeable.

\subsection{Personal Private Space (PPS)}

When it comes to the 3rd dimension of the 3D model, the UPL of the BGM is replacing by a PPS module as illustrated in the fig 24 below but sharing the rest of the infrastructure of the BGM. The module design makes the UPL as real connectors between Virtual Enterprise and Freelancer, SME adapting the same model instantly. Small agent fee might apply for out-ofstandard participants but it is small money comparing to current cost in connectivity as mentioned in equation (8). By adapting the 1+6 infrastructure any entity in nested society can "park" to any stage of the supply chain freely in value chain and "park" as in freelancer as participant of the virtual organization. Inside the PPS, it contains 4 modules: "Networking", "Personal Center", "Product Manager", and "Article Manager" which any PPS can grouped together to form VHRO, perform knowledge management, and even Production Development. Under the PPS, the knowledge is resident in the PPS and he has options to continue to sharpen his profile or group with others resources to shot for opportunities.

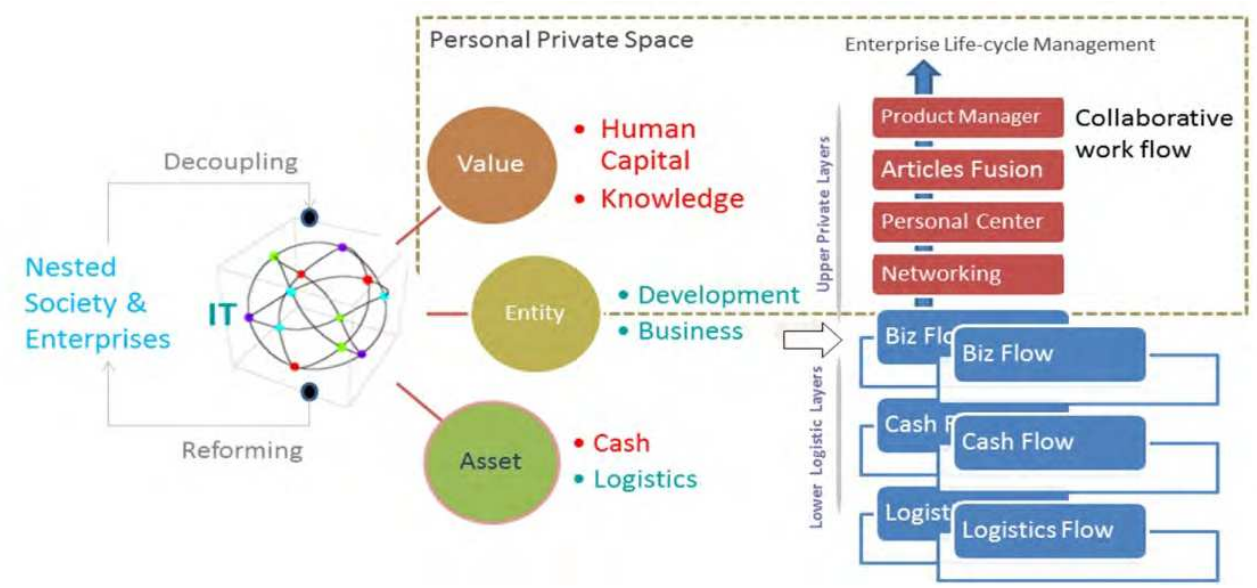

Fig. 24. The "Personal Development Space" over the Business Gateway Model

The rest of the PPS connected to in fig 24 is the reference ecosystem that a group of PPS are parked together as is an example of Talent.net community in fig 22 that provide full Enterprise Life Cycle (ELM) service to grow to conduct career development path. With the features in the reference ecosystem, each individual freelancer or SME is similar staying in a large company supporting departments such as Human Resource (Virtual Human Resource Organization here), Procurement (Supply Chain here), Facility (such as Warehouse here), Collaborative tools (Such as Forum, VoIP, HCT for product project management).etc. Without proper supporting resources, individual with PPS would not be practically having 
full coverage in learning cycle to be competitive with the one who claim up the social ladder providing by enterprise.

Beside the administrative support in workflow collaboration, the ecosystem also act as the coordinator to fanning in new technology such as the Dynamic Gateway Group (DGG) for unify communication techniques, Internet of Things (IoT) for next generation sensor network, etc in Fig 24. The ecosystem is also facilitated what the member needs in common such as academic support from School in Supply Chain System Engineering (SCSE), and, bargaining with the 3PL to provide logistics services for lower Logistics Level portion of the PPS model. The distinguished design of this ecosystem is they are all adapting the same under layer IT model and users in the ecosystem are identical in architecture except the differentiable workflow embedded. LLL service provide who is IT compatible to the BGM gateway is connectable between Enterprise and directly to freelancer under BGM and PPS architecture.

\subsection{Highly scalable supplier life cycle management}

For large enterprise with a school of SME, freelancers they need to manage, it is always a big challenge where it is not big enough in business transaction to justify the cost of IT connectivity for workflow collaboration in current IT connectivity model. That is another main reason of causing that poor result in B2B system integration in Table 1. With the IT model and SCSE architecture in this chapter the problem can be easily resolved with the reference application in fig 25. It is a deal-mode, hybrid structure where the yellow color on the top-right corner is still the IT setup today roughly with $20 \%$ of supplier but occupying $80 \%$ of the revenue according to the $80 / 20$ rule.

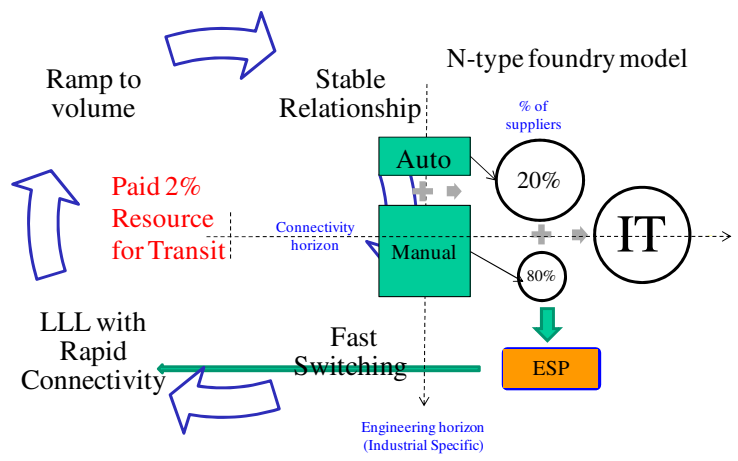

Fig. 25. The Supplier Life Cycle Management with dual routes

In the chart, it provides a cycle to manage the new suppliers. That explains the source of IT connectivity challenges. The $20 \%$ suppliers consume $80 \%$ of the resources and only leave the $20 \%$ for the rest. For company like Texas Instruments, ADI, or Players working in analog industry with thousands of product lines, that is the major bottleneck of business development and scale up when managing SME suppliers manually is an unsolvable solution in productivity.

The left side of fig 25 applying the SCSE architecture is the suggested solution to high product mixes industry with small qty in technological segment. The manually operating production line can adapt the model here with appropriated LLL service provide to kick 
start the "Cover what you do best, Link to the rest" cycle in on-demand basis. Once a supplier is growing up in volume as indicated, it reaches the criteria of entering the "Ntype" to become $\mathrm{N}+1$ of the matured, IT pool. That completes the cycle seamlessly under the IT and cost constraints. The ESP is an Engineering Service Provider it could be either performing by internal Business Unit who responsible for the product line or hired contractor out of the dual cycle.

\subsection{Low maturity level in facility supporting participating production}

The IT infrastructure in this section has covered the full spectrum of the SCSE architecture and what it needs to connect to PPS therefore connectable to public space to complete the connectivity all the way to nested society. This is why the research team is "accidentally" find the redefined SCSE is the physics of the nested society when it has to resolve the SME part of the connectivity issue to work with SME especially the world is decoupling into smaller size of enterprise, both dominantly and globally. The IT model also demonstrates the scalability because of the "parking" concept under the same 1+6 flow model with the cost equation (9) and very unique feature such as "pretending" capability to allow dynamic skin to participate virtual enterprise activities via the VHRO model. Covering full ELM cycle and reference design in ecosystem empower individual to have equal power in IT to compete with large enterprise. The unique segregated network design is highly simplified the network size and complexity, hardware accelerated network provide real power of huge network, therefore IoT reference model is doable. The research team suggests the maturity of the current design in participatory Production is moderated after all years test and validation. It is just time to release to "production" to have more field test where the research team the maturity level in the field is low. Unfortunately, the study shows the higher the N-factor of the participatory Production, the stronger dependency of the public facility to make it success. However, it is also a bright side since it implies it is an attractive business to players who wants this market because of the positive loop of business model: High-N factor value chain pair with Participatory Production service provider is the winning pair of the global competition. That is opportunity.

\section{Conclusion}

The Participatory Production in this chapter representing the most complicated value network on the extreme side of private space and it has been demonstrated by peeling off layer by layer systematically through the document hierarchy. The System Engineering approach to conduct requirements, allocation, and deployment process is a self-explanatory, a best-practice approach like the DoD 4245.7-M standard to delivery framework for implementation. For enterprise, this chapter provides a rock solid path to transform into Triple-A virtual enterprise in an ultra high degree of freedom with on-demand human capital capability. For an individual, this chapter provides a full scalable career path from freelancer, SME to large enterprise in a participatory manner. For SCSE, the bidirectional pair in the 3D model determines its capability of being the physics of running a complicated complex operation. As a solution space including both enterprise and an individual, SCSE is nominated as the best "physics" candidate to running a nested society. On the other hand, the SCSE is the first user-centric framework that transforms the IT-centric languages into the operation domain languages to help an executive walking out of the mind map to make the 
right decision himself directly not through the IT or a consultant to clear out the accountability. Although the model in this chapter is only covering the detail in the postmilestone $\mathrm{C}$ of the acquisition cycle, the maturity of the overall SCSE and the associated IT model is sufficient as the first set of infrastructure to support the nested society to start the iterating process of improvement. This chapter concludes that the nested society as the end point of the IT revolution is set when the SCSE as the physics of running the nested society is confirmed.

Another purpose of this publication is to accelerate the fusion process of the IT revolution since the search team also suggests the review process of the academic system today is one of the barriers that slow the fusion process. If human capital crossing 3 disciplines is a natural barrier of any review board, it implies that any topic, paper, proposal that has more than 3 disciplines will be naturally denied since no eligible referees can be found adequately. Or, the topic like the physics of running the nested society, triple-A enterprise might take decades to bubble up to the top of the hierarchical tree in the current academic structure. That might explain why only $10 \%$ of samples in the literature research going the multiple disciplines approach. For a super scale management solution like that, DoD stepped out to carry out the DoD 4245.7-M standard is an good example to accelerate the complex solution. DoD is responsible for tax money therefore accountable to the project management to invent the standard for a defense project. But for the nested society or Participatory Production challenges today, who should be accountable in the government level to lead the way when the competitor of enterprise is an aggressive governor not the war between enterprises? The game rules have changed and a new game plan is required in the "FREE economy" campus.

\section{Acknowledgments}

I would like to thank the many groups that made the SCSE and KNOWLEDGE CONTAINER hypothesis become a reality since 2003. The First is the engineering support from the Flow Fusion Research Laboratory for their expertise, advice in the skeleton and architecture design: Dr. Lu's nerve network and Knowledge model; SCP system designer Carol $\mathrm{Wu}$, UCC expert Xiao Wu, system architect David Yen and many volunteers not listed here for valuable discussions, sharing their insights, and meeting over the weekend. The Second, is the academic support from Dr. Stracener, who brought up the System Engineering idea to merge with the Supply Chain, and Dr. Yu, who gave all the advice on supply chain when the fusion process is performing. The third group are the experimental facilities such as Texas Instruments, Foxcavity, EDS, AIML, EA etc to leverage the lessons learned from their industries. The Fourth, and not the least, is the implementation team in Nanjing, led by Chris Chen in community technology, Lionic in hardware-accelerated network security, ZyCoo in VoIP platform, Taohua in the collaborative set top box, and more participatory partners to let the dream go live

\section{References}

Chan, L.K., S.W. Cheng and F.A. Spiring (1988), “A New Measure of Process Capability: Cpm," Journal of Quality Technology, 20,162-175

Christopher, M.(1992) "Logistics and Supply chain Management", Pitman Publishing, London 
Croom, S. (2000) "The Impact of Web-based Procurement on the Management of Operating Resources Supply", Journal of Supply Chain Management; Tempe, Vol. 36, Issue 1, pp. 413

Dertouzos, M. L. (2001) “The Unfinished Revolution: Human-Centered Computers and What They Can Do For Us". MIT, HarperCollins

Enslow, Beth (Aug 2006) "The Global Supply Visibility and Performance Benchmarking Report", Aberdeen Group

Gulati, R.(2008), "Silo Busting: Transcending Barriers to Build High-Growth, CustomerCentric Organization," Evanston, Northwest University, 2007. To be published by Harvard Business School Press in 2008

Hajime Kita, Mikihiko Mori, Takaaki Tsuji (2008), "Toward Field Informatics for Participatory Production," Informatics Research for Development of Knowledge Society Infrastructure, International Conference on, pp. 67-72, International Conference on Informatics Education and Research for Knowledge-Circulating Society.

Houlihan, J. (1974) "Supply Chain Management". Proceedings of the 19th Int. Tech.Conference BPICS, pp. 101-110

Kai, Lukoff ( Sept. 2010) "Alibaba and eBay: More competition than cooperation, despite a show of friendship",San Francisco, VentureBeat

Jarvis, Jeff (Feb 2007). "New rule: Cover what you do best. Link to the rest", BuzzMachine Lamming, R.C. (1993) "Beyond Partnership: Strategies for Innovation and Lean Supply",Prentice-Hall,Hemel Hampsted

Lee, Hau L.(Oct. 2004), “The Triple-A Supply Chain”, HBR

Li,Wei and Cheng,Jinhua (Jul 2003) "The SMEs Development and China Economy",USAChina Business Review(Journal), Volume 3, No.7,ISSN 1536-9048

Matthews, Julian (March 2008) "Alibaba Group - China's E-Commerce Giant", the Chindians, Kuala Lumpur, the confluence of news on China and India, March 21, 2008

Merco Press (May 2011),"China became world's top manufacturing nation, ending 110 year US leadership", HIS Global Insight, UTC, May 14th 2011

Milesa, Raymond E. and Snow, Charles C.(March 200\&), “Organization theory and supply chain management: An evolving research perspective", Journal of Operations Management, Volume 25, Issue 2, Pages 459-463

Nolan,Peter; Liu, Chunhang;Zhang,Jin (2007) “The Global Business Révolution, the Cascade Effect, and the challenges for firms from developing countries ", Oxford Journal , Vol. 32, Issue 1, Pp. 29-47

Nolan,Peter (2008), "Capitalism and freedom: the contradictory character of globalization", Anthem

Oscar, A., Saenz, A. and Chen, C.S. (June 2004) "Framework for Enterprise Systems Engineering" LACCEI, Miami, FL

Pisani, Jo (March 2006) "Industry Overview-improving focus", Pharmaceutical Outsourcing Decisions, SPG Media Limited

Porter M. E. (1998) «Competitive Advantage CREATING AND SUSTAINING SUPERIOR PERFORMANCE », Free Pr, ISBN: 0-684-84146-0

Raynor, William (Feb. 2003) "Globalization and the Offshore Outsourcing of White-Collar Jobs", Business Week 
Rebovich, George Jr. (Nov. 2005) “Enterprise Systems Engineering Theory and Practice , Volume 2: Systems Thinking for the Enterprise: New and Emerging Perspectives “, MITRE

Slack,Nigel (Dec. 1995) "Operations Strategy" (1st Edition), Prentice Hall

Slack, N., Chambers, S., Harland, C, Harrison,A. and Johnstone, R., (1995) "Operations Management",Pitman,London

Supply Chain Operation Reference (SCOR) Model, http://www.supply-chain.org

Tan, K.C. (2001) "A framework of supply chain management literature", European Journal of Purchasing and Supply Management, 7(1), 39-48

Tsai P. T and Lu, T. M. (2011) “A Self-Aligned Business Gateway Model to Manage Dynamic Value Chain and Participatory Production: Knowledge Management Prospective to Distributed Organization",

Tsai, T.P., Lu, M. T., and Stracener, J. (March 2011) “A Simple Knowledge Container Skeleton to Build a Nested Society: Bridging Personal Development to Participatory Production", 7th International Conference on Technology, Knowledge and Society, Bilbao, Spain

Tsai, T. P., Stracener, J., Yu, J., and Wang, F. (April 2008), "Transforming IDM into Distributed Value Network: Framework Forming a New Branch and a Case Study in High Precision Analog Semiconductor Industry », CSER 2008 Conference.

Tsai, T.P., Yu, J., Stracener, J. and Wang, F.C.(June 2008). Delivery quality product in value chain: a case study to rebuild broken quality system in piecewise organization. Proceedings of International Conference on Awareness in Product Development and Reliability, Chengdu, China.

Tsai, T.P., Yu, J., and Stracener, J. (Dec. 2009) “BACK TO BASIC: MANAGING SUPPLY CHAINS COLLABORATION BYCONTINUAL IMPROVEMENT IN OVER-THENET OPERATION MEETING", DET2009, Hong Kong

Tsai, T. P. and Wang, F.(2004), "Improving Supply Chain Management: A Model for Collaborative Quality Control," IEEE/ ASMC 2004, pp. 36-42.

Tsai, T.P., Yu, J. and Yun, S. (2008), "Proactive Supply Chain planning: a Dynamic Quantitative Planning Model," The 3rd World Conference on Production and Operations Management, Tokyo, Japan

Viswanathan, Nari (August 2008) "Process Collaboration in Multi-Enterprise Supply Chains - Leveraging the Global Business Network", Aberdeen Research

Willoughby,W. J. Jr.(1985) "DoD 4245.7-M: Transition from Development to Production", Task Force on "Transition from Developement to Production", 1982 Defense Science Board, published by BMP

Wu, Jeffrey (August 2008), “Economic uncertainties stimulate LCD-TV outsourcing”. iSuppli Corp 


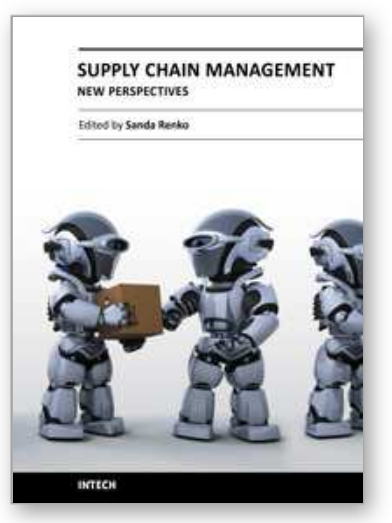

\author{
Supply Chain Management - New Perspectives \\ Edited by Prof. Sanda Renko
}

ISBN 978-953-307-633-1

Hard cover, 770 pages

Publisher InTech

Published online 29, August, 2011

Published in print edition August, 2011

Over the past few decades the rapid spread of information and knowledge, the increasing expectations of customers and stakeholders, intensified competition, and searching for superior performance and low costs at the same time have made supply chain a critical management area. Since supply chain is the network of organizations that are involved in moving materials, documents and information through on their journey from initial suppliers to final customers, it encompasses a number of key flows: physical flow of materials, flows of information, and tangible and intangible resources which enable supply chain members to operate effectively. This book gives an up-to-date view of supply chain, emphasizing current trends and developments in the area of supply chain management.

\title{
How to reference
}

In order to correctly reference this scholarly work, feel free to copy and paste the following:

Timothy P. Tsai (2011). Supply Chain System Engineering: Framework Transforming Value Chain in Business Domain into Manageable Virtual Enterprise and Participatory Production, Supply Chain Management - New Perspectives, Prof. Sanda Renko (Ed.), ISBN: 978-953-307-633-1, InTech, Available from: http://www.intechopen.com/books/supply-chain-management-new-perspectives/supply-chain-systemengineering-framework-transforming-value-chain-in-business-domain-into-manageabl

\section{INTECH}

open science | open minds

\author{
InTech Europe \\ University Campus STeP Ri \\ Slavka Krautzeka 83/A \\ 51000 Rijeka, Croatia \\ Phone: +385 (51) 770447 \\ Fax: +385 (51) 686166 \\ www.intechopen.com
}

\author{
InTech China \\ Unit 405, Office Block, Hotel Equatorial Shanghai \\ No.65, Yan An Road (West), Shanghai, 200040, China \\ 中国上海市延安西路65号上海国际贵都大饭店办公楼 405 单元 \\ Phone: +86-21-62489820 \\ Fax: +86-21-62489821
}


(C) 2011 The Author(s). Licensee IntechOpen. This chapter is distributed under the terms of the Creative Commons Attribution-NonCommercialShareAlike-3.0 License, which permits use, distribution and reproduction for non-commercial purposes, provided the original is properly cited and derivative works building on this content are distributed under the same license. 